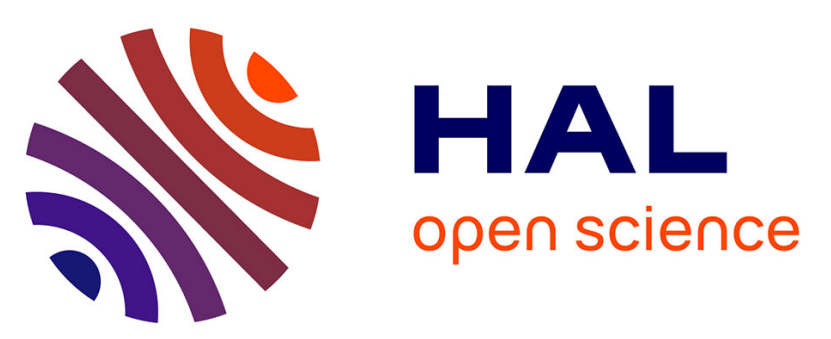

\title{
Assessment of the barrier effect caused by underground constructions on porous aquifers with low hydraulic gradient: A case study of the metro construction in Barcelona, Spain
}

Jordi Font-Capo, Estanislao Pujades, Enric Vàzquez-Suñé, Jesús Carrera, Violeta Velasco, Daniel Montfort

\section{To cite this version:}

Jordi Font-Capo, Estanislao Pujades, Enric Vàzquez-Suñé, Jesús Carrera, Violeta Velasco, et al.. Assessment of the barrier effect caused by underground constructions on porous aquifers with low hydraulic gradient: A case study of the metro construction in Barcelona, Spain. Engineering Geology, 2015, 196, pp.238-250. 10.1016/j.enggeo.2015.07.006 . hal-01181349

HAL Id: hal-01181349

https: / hal-brgm.archives-ouvertes.fr/hal-01181349

Submitted on 30 Jul 2015

HAL is a multi-disciplinary open access archive for the deposit and dissemination of scientific research documents, whether they are published or not. The documents may come from teaching and research institutions in France or abroad, or from public or private research centers.
L'archive ouverte pluridisciplinaire HAL, est destinée au dépôt et à la diffusion de documents scientifiques de niveau recherche, publiés ou non, émanant des établissements d'enseignement et de recherche français ou étrangers, des laboratoires publics ou privés. 


\section{Accepted Manuscript}

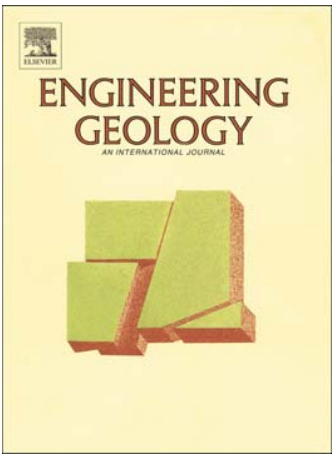

Assessment of the barrier effect caused by underground constructions on porous aquifers with low hydraulic gradient: A case study of the metro construction in Barcelona, Spain

Jordi Font-Capo, Estanislao Pujades, Enric Vàzquez-Suñé, Jesús Carrera, Violeta Velasco, Daniel Montfort

PII: $\quad$ S0013-7952(15)30015-6

DOI: doi: $10.1016 /$ j.enggeo.2015.07.006

Reference: $\quad$ ENGEO 4098

To appear in: $\quad$ Engineering Geology

Received date: $\quad 4$ August 2014

Revised date: 2 June 2015

Accepted date: 15 July 2015

Please cite this article as: Font-Capo, Jordi, Pujades, Estanislao, Vàzquez-Suñé, Enric, Carrera, Jesús, Velasco, Violeta, Montfort, Daniel, Assessment of the barrier effect caused by underground constructions on porous aquifers with low hydraulic gradient: A case study of the metro construction in Barcelona, Spain, Engineering Geology (2015), doi: 10.1016/j.enggeo.2015.07.006

This is a PDF file of an unedited manuscript that has been accepted for publication. As a service to our customers we are providing this early version of the manuscript. The manuscript will undergo copyediting, typesetting, and review of the resulting proof before it is published in its final form. Please note that during the production process errors may be discovered which could affect the content, and all legal disclaimers that apply to the journal pertain. 
Assessment of the barrier effect caused by underground constructions on porous aquifers with low hydraulic gradient: A case study of the metro construction in Barcelona, Spain

Jordi Font-Capo ${ }^{1,2}$, Estanislao Pujades ${ }^{2}$, Enric Vàzquez-Suñé ${ }^{2}$, Jesús Carrera $^{2}$, Violeta Velasco $^{2}$, Daniel Montfort ${ }^{3,2}$.

${ }^{1}$ AMPHOS 21 Consulting S. L., Barcelona, Spain.

2 GHS, Institute of Environmental Assessment and Water Research (IDAEA), CSIC, Barcelona, Spain

${ }^{3}$ BRGM, Direction de Risques et prevention. Orléans, France.

Corresponding author: Enric Vàzquez Suñé

Phone: +34 934006100

Fax: +34 932045904

e-mail: enric.vazquez@idaea.csic.es 


\begin{abstract}
Construction of tunnels can impact aquifers because of the changes produced in the natural groundwater behavior. The drain effect, which is one of the most important impacts, can be eliminated using a tunnel-boring machine (TBM) to drill a tunnel with an impervious lining. However, the use of impermeable linings results in aquifer obstruction, giving rise to the barrier effect, which may cause an increase and decrease of the hydraulic head upgradient and downgradient of the tunnel, respectively. This modification of the hydraulic head, which can be predicted analytically and is proportional to the natural hydraulic gradient of the aquifer perpendicular to the tunnel $\left(i_{N}\right)$ (before it is constructed), is negligible for aquifers with values of $i_{N}$ that are very small or null (approximately 0). In these cases, the analytical solutions are not useful to estimate the real impact because the head distribution is not largely affected.

This study proposes a methodology to evaluate the hydrogeological impact produced by the construction of underground impervious structures in aquifers, which have a small or null $i_{N}$. The method, which is based on the analysis of the groundwater response to pumping tests performed before and after construction, was tested in a stratified porous aquifer and was used along with numerical modeling to assess the barrier effect in an experimental site (Sant Cosme, El Prat de Llobregat, Barcelona). The impact on the head distribution was negligible. However, the reduction of the connectivity was considerable. Pumping tests can determine the changes in aquifer connectivity caused by the construction of an underground impervious structure. The behavior of the groundwater during the post-tunneling pumping changes with regards to the pre-tunneling tests. A delay in the response to the pumping and a decrease of the drawdown are observed in the piezometers located on the opposite side of the tunnel where the well is placed, whereas an increase of drawdown occurs in the piezometers situated on the same side of the well. The procedure explained in this paper reveals a useful tool for determining the impact caused by underground impermeable constructions in aquifers, where $i_{N}$ is small or even 0 .
\end{abstract}

Keywords: Tunnel, Barrier effect, Pumping Test, TBM, porous aquifer 


\section{Introduction}

Most of the underground infrastructures constructed in the metropolitan area of Barcelona in the last decade have been excavated below the water table. The present study arose from a hydrogeological survey performed during the construction of the underground line L-9 in the Llobregat Delta (Figure 1), which is located in the southern part of Barcelona (Spain). The tunnel, which was excavated with a Tunnel Boring Machine (TBM), cuts a large section of the Llobregat Delta Shallow Aquifer. The potential hydrogeological impacts caused by tunnel drainage, barrier effects or other sources should therefore be quantified.

The hydrogeological impacts caused by a tunnel depend on the properties of the lining, aside from the aquifer properties. If the lining is permeable, tunnel inflows could cause a piezometric drawdown (Goodman et al., 1965; Gargini, et al., 2008; Kvaerner and Snilsberg, 2008; Yang, et al., 2009; Raposo, et al., 2010). If the tunnel has an impervious lining, this can create a barrier effect by partial or total reduction of the aquifer section (Marinos and Kavvadas, 1997; Vàzquez-Suñé, et al., 2005, Carrera and Vàzquez-Suñé, 2009; Deveughele, et al., 2010), decreasing 1) the effective transmissivity of the aquifer (the sum of the transmissivity of the different geological layers) in the site where the tunnel is located and 2) the hydraulic connectivity between both sides of the construction. High values of hydraulic connectivity between two points signify that changes performed at one of the points are easily transmitted to the other point. The main impact of the barrier effect consists of an increase in the hydraulic head on the upgradient side of the construction and a decrease on the downgradient side (Ricci, et al., 2007). Under ideal conditions, the increase in the upgradient has the same magnitude as the decrease in the downgradient. The distribution on the impact varies depending on the boundary conditions of the aquifer (Pujades et al., 2012). 
Drawdown caused by the drain effect or by the barrier effect (downgradient) could give rise to a number of problems, e.g., a) ground settlements caused by an increase in the effective stress (Zangerl, et al., 2003, 2008a, and 2008b; Mokni, et al., 2013, Carrera and Vàzquez-Suñé, 2009), b) drying of wells, springs (Gargini, et al., 2008; Yang, et al., 2009; Raposo, et al., 2010) and wetlands (Kvaerner and Snilsberg, 2008), c) seawater intrusion into coastal aquifers and d) swelling as a result of gypsum precipitation in anhydrite rock massifs (Butscher, et al., 2011).

Head increase on the upgradient side caused by the barrier effect could lead to a) floods in surface and ground structures, b) soil salinization (Vàzquez-Suné, et al., 2005; Carrera and Vàzquez-Suné, 2009), c) soil contaminant lixiviation from piezometric cleaning (Navarro, et al., 1992), and d) changes in the natural groundwater behavior that can mobilize contaminants (Chae, et al., 2008; Epting, et al., 2008).

It is possible to assess the impact caused by tunnel inflows on surface water (Gargini, et al., 2008) and groundwater (Attanayake and Waterman, 2006). Analytical (Bear, et al., 1968; Custodio, 1983) and numerical methods (Molinero, et al., 2002; Epting, et al., 2008; Yang, et al., 2009; Raposo, et al., 2010; Font-Capó, et al., 2011) can be used for inflow quantification. The impact caused in the hydraulic head by the barrier effect can also be assessed numerically (Bonomi and Bellini, 2003; Merrick and Jewell, 2003, Tubau, 2004 and Ricci, et al., 2007) and analytically (Marinos and Kavvadas, 1997; Deveughele, et al., 2010 and Pujades, et al., 2012).

The hydraulic head variation produced by the barrier effect can be expressed mathematically as the difference between the undisturbed hydraulic gradient and the hydraulic gradient once the underground structure is constructed (Pujades, et al., 2012). The magnitude of this variation is proportional to the natural groundwater gradient perpendicular to the construction $\left(i_{N}\right)$. A higher gradient increases head variation and vice versa. Therefore, at 
sites with small gradients, the impact in the hydraulic head caused by underground impervious structures is negligible. However, these constructions alter aquifers reducing their connectivity. Consequently, the assessment of the barrier effect, quantifying only the hydraulic head variation, is very limited including the corrective measures adopted to reduce it. In addition, because $i_{N}$ is necessary to apply the analytical solutions, these may fail at sites with small $i_{N}$ as a result of errors associated with the field measurements (inaccuracies in the altimetry of piezometers, in measurements, and in head fluctuations, a result of natural or anthropogenic causes). These errors, which may occur at other situations, are more important (regarding the magnitude of the barrier effect) at sites with small $i_{N}$.

During the construction of the tunnel for Line 9 of the metro in Barcelona, a small $i_{N}$ was observed at some of the construction sites. Concretely, this fact was noticed at the neighborhood of Sant Cosme (El Prat de Llobregat, Barcelona). Given that it was necessary to predict the impact of the construction and that the analytical predictions were not believable (because of the small $i_{N}$ ), a procedure based on pumping tests was followed to assess the impact of the construction on the aquifer. The main conclusion is that the reduction in connectivity and effective transmissivity produced by the underground impervious structures in aquifers can be evaluated by comparing the drawdown evolution that occurred during pumping tests performed before and after the construction. This method does not depend on $i_{N}$.

This paper seeks to 1) quantify the impact of an impermeable tunnel constructed with a TBM on the steady state heads in a real site, and 2) propose a method to quantify the impact caused by an impervious tunnel on the connectivity of an aquifer by using pumping tests.

\section{Problem Statement (basic concepts)}


2.1. General description of the barrier effect

Pujades et al. (2012) define the barrier effect $\left(s_{B}\right)$ as the increase in head loss (or drop) along flow lines caused by the reduction in conductance associated with an underground construction. Therefore, the barrier effect $\left(s_{B}\right)$ is defined mathematically as

$$
s_{B}=\Delta h_{B}-\Delta h_{N}
$$

where $\Delta h_{B}$ is the head drop across the barrier and $\Delta h_{N}$ is the head drop between the same observation points in natural conditions (prior to construction). The magnitude of $s_{B}$ depends on the situation of the observation points with regard to the barrier because the maximum rise or drop of the head is produced in the center of the barrier. It is possible to differentiate between local $\left(s_{B L}\right)$ and regional $\left(s_{B R}\right)$ barrier effects considering the distribution of the impact. A detailed explanation of the barrier effect can be found in Pujades et al., 2012.

2.2. Main impacts caused in aquifers by impervious structures (synthetic numerical model)

This subsection demonstrates the main groundwater impacts caused by an underground impervious structure. A synthetic 2D numerical model of a homogeneous aquifer crossed by an impervious tunnel is used to reveal these impacts. The numerical model was built using the finite element code TRANSIN-IV (Medina and Carrera, 1996, Medina and Carrera, 2003) with its visual interface VISUAL TRANSIN (GHS-UPC, 2003). The model consists of a square aquifer (2000 x 2000 m). A north-south natural flow is imposed, applying leakage conditions on the northern and southern boundaries, resulting in a hydraulic gradient of 0.005 . The transmissivity and the storage coefficient of the aquifer are $1 \mathrm{~m}^{2} / \mathrm{d}$ and $10^{-4}$, respectively. The tunnel, which is $10 \mathrm{~m}$ thick, is located in the middle of the model and 
separates the northern from the southern side (Figure 2a). One observation point is located at each side of the tunnel (PZ1 is downgradient and PZ2 is upgradient) (Figure 2b); both are placed $5 \mathrm{~m}$ from the tunnel. The tunnel is simulated as an area with a value of effective transmissivity $\left(T_{\text {eff }}\right.$ ) lower than that of the aquifer. This methodology allows for the simulation of different insertion depths by only varying the $T_{\text {eff }}$ of the tunnel, which is computed considering the transmissivity of the aquifer and the thickness of the aquifer cut by the tunnel (e.g., if the tunnel cuts half of the aquifer and its transmissivity is $1 \mathrm{~m}^{2} / \mathrm{d}$, the $T_{\text {eff }}$ used to model the tunnel will be $0.5 \mathrm{~m}^{2} / \mathrm{d}$ ). Following this procedure, three different insertion depths of the tunnel are modeled by adopting three different values for $T_{\text {eff }}$. The insertion depths and values of $T_{e f f}$ are 1) half of the aquifer $\left.\left(T_{\text {eff }}=0.5 \mathrm{~m}^{2} / \mathrm{d}\right), 2\right) 90 \%$ of the aquifer $\left(T_{\text {eff }}=0.1 \mathrm{~m}^{2} / \mathrm{d}\right)$ and 3$) 99 \%$ of the aquifer $\left(T_{\text {eff }}=0.01 \mathrm{~m}^{2} / \mathrm{d}\right)$.

Some simulations are constructed to show the impact on the natural flow. The entire simulation period lasts 50 days and the tunnel is implemented into the model on the $10^{\text {th }}$ day. Hydraulic head increases upgradient and a symmetrical drop occurs downgradient (Figure 3a). The barrier effect increases as $T_{\text {eff }}$ decreases. There is an increase in the gradient through the tunnel area, especially when $T_{\text {eff }}$ is low (Figure 2c).

Additionally, some simulations are performed to also demonstrate the impact in the connectivity by simulating pumping tests (with and without the tunnel) and comparing the drawdown response. The differences in the drawdown magnitude and the time response allow the variation of the connectivity to be quantified. The pumping well is placed on the southern side of the tunnel at a distance of $5 \mathrm{~m}$. The observation points are located $20 \mathrm{~m}$ from the well (Figure 2b). The pumping rate is $1 \mathrm{~m}^{3} / \mathrm{d}$ for 10 days. As expected, the drawdown at the observation points depends on their position with respect to the well and the tunnel. 
Drawdown on the side where the well is placed (PZ1) increases when $T_{\text {eff }}$ decreases (Figure 3b), whereas drawdown decreases on the opposite side of the tunnel (PZ2) if the $T_{\text {eff }}$ is reduced (Figure 2d, Figure 2e and Figure 3c). Therefore, the groundwater gradient through the tunnel increases when the value of $T_{\text {eff }}$ decreases. The drawdown response in time is also affected by $T_{e f f}$ because lower values of $T_{\text {eff }}$ cause a delay at the observation point placed on the opposite side of the tunnel with respect to the well (PZ2). This fact agrees with the Cooper and Jacob method (1946) for the interpretation of pumping tests because lower values of $T_{\text {eff }}$ cause an increase of $t_{0}$. The method consists of plotting the measured drawdown versus the logarithm of time, drawing a straight line through the later time data points and extending it backward to the point of zero drawdown (time axis intercept), which is designated $t_{0}$ (Meier, et al., 1998; Sánchez-Vila, et al., 1999).

\subsection{Analytical solutions}

Several authors propose analytical solutions to quantify the barrier effect (e.g., Carrera and Vàzquez-Suné, 2009; López, 2009; Deveughele, et al., 2010, Pujades et al., 2012). Among them, Pujades et al. (2012) studied the local and regional barrier effects on natural flow (not perturbed) and proposed analytical solutions to compute the effects. Equations 2 and 3 allow us to compute the regional $\left(s_{B R O}\right)$ and local $\left(s_{B L O}\right)$ barrier effects that occur between the boundary of the aquifer and the barrier, whereas Equation 4 enables us to compute the head loss produced when the groundwater flows under or around the barrier $\left(s_{B I}\right)$ (depending on the length partially cut by the barrier). The total impact is obtained by adding both values $\left(s_{B R O}\right.$ or $\left.s_{B L O}+s_{B I}\right)$. 


$$
\begin{aligned}
& s_{B R O}= \begin{cases}0 & \text { if } \quad b_{b D} \leq 0.1 \\
\frac{2 i_{N} b}{3 \pi} \ln \left(\frac{1}{5 \pi b_{b D}\left(1-b_{b D}\right)^{6}}\right) & \text { if } \quad b_{b D}>0.1\end{cases} \\
& S_{B L O}= \begin{cases}2 b_{b D} i_{N} b & \text { if } \quad b_{b D}<0.28 \\
i_{N} b \sqrt{\frac{3}{8} \ln \left(\frac{2 b_{b D}^{0.29}}{b_{a D}^{2}}\right)} \quad \text { if } \quad b_{b D} \geq 0.28\end{cases} \\
& s_{B I}=i_{N} L_{B}\left(\frac{b}{b_{a}}-1\right)
\end{aligned}
$$

where $L_{B}$ is the width of the barrier, $i_{N}$ is the natural groundwater gradient perpendicular to the barrier (measured before the construction), $b$ is the thickness of the aquifer (or width, depending on the length partially cut by the barrier), $b_{a}$ and $b_{b}$ are the open and cut fractions of the aquifer, respectively, and finally, $b_{b D}=\left(b_{b} / b\right)$ and $b_{a D}=\left(b_{a} / b\right)$ are open and cut fractions of the aquifer expressed in dimensionless form. Note that the distances $\left(b_{a}, b_{b}\right.$ and $\left.b\right)$ must be corrected using the anisotropy factor when the soil is heterogeneous in the direction followed by the flow to cross the barrier. The correction is accomplished by multiplying the real distance by the anisotropy factor. More information about these solutions can be obtained in Pujades et al., 2012.

Pujades et al. (2012) also describe the relationship between $s_{B}$, the effective hydraulic conductivity of the aquifer $(k)$ and the effective hydraulic conductivity of the area affected by the barrier $\left(k_{B}\right)$ as

$$
\frac{s_{B}-i_{N} L_{B}}{i_{N} L_{B}}=\frac{k}{k_{B}}-1
$$


Equations proposed by Pujades et al. (2012) to compute $s_{B}$ assume that the flow through the aquifer remains unchanged. Thus, if the local flow is perturbed by additional factors (i.e., recharge or pumping), $s_{B}$ cannot be computed by these methods. These equations also consider that the shape of the underground structure is a square, which must be taken into account in the case of circular tunnels.

However, it is difficult to analytically assess the barrier effect when $i_{N}$ is very low because it $\left(i_{N}\right)$ must be known exactly to apply the equations. Given that $i_{N}$ is subjected to errors associated to inaccuracies in the altimetry of piezometers, in measurements and in head fluctuations resulting from natural or anthropogenic causes and that these errors can be proportionally higher regarding the magnitude of $i_{N}$, the analytical assessment of the barrier effect can fail.

\section{Application}

3.1. Geographical setting and the main characteristics of the construction

The study area (pilot site) consists of a section of Line 9 of Barcelona's Underground located in the neighborhood of Sant Cosme at El Prat del Llobregat, which forms part of the Barcelona's metropolitan area (NE Spain) (Figure 1). This area was ideal for the application of our study because: 1) the geological and hydrogeological conditions were well known, 2) there was sufficient time to drill boreholes and perform pumping tests before the passing of the TBM and 3) there were no surface infrastructures at the site during the study (i.e., easy access to drill boreholes and conduct pumping tests). 
The tunnel was drilled with a 9.4-m diameter TBM type Earth Pressure Balance (EPB). This machine is adapted to drill in soft deltaic materials below the groundwater level (Di Mariano, et al., 2009). The top of the tunnel was located $15 \mathrm{~m}$ below ground level (b.g.l.).

\subsection{Geological settings}

The pilot site was located in the Llobregat Delta, which is a quaternary formation considered to be a classic example of a Mediterranean Delta controlled by fluvial and coastal processes. This is a Holocene depositional system that was also active during the Pleistocene and rests unconformably on Paleozoic to Pliocene deposits (Gámez, 2007). The sedimentation of the Llobregat Delta was primarily controlled by glacio-eustatic sea level changes (Manzano, et al., 1987; Gámez, et al., 2009; Custodio, 2010). Geological studies (e.g., Marques, 1984; Simó, et al., 2005; Abarca, et al., 2006) inferred that the delta is formed pirmarily by two detritical complexes: a Pleistocene Lower Detritical Complex (LDC) (Q3, Q2, and Q1 in Figure 4) and a Holocene Upper Detritical Complex (UPD) (Q4 in Figure 4).

The Lower Detritical Complex (LDC) is composed of fluvial gravels interbedded with yellow and red clays that grades to offshore clays (Marques, 1984; Simò, et al., 2005; Gámez, 2007). This detritical complex contains several incisive fluvial systems separated by marginal marine strata and it is associated with three paleodeltas currently located seawards of the present shoreline (Vàzquez-Suné, et al., 2006; Abarca, et al; 2006).

The Upper Detritical Complex (UPD) consists of the typical stratigraphic delta sequence and is composed of four lithofacies, from bottom to top, transgressive sands, Prodelta silts, Delta Front sands and silts and an uppermost unit made up of Delta Plain gravels and sands, floodplain fine sands, silts and red clay (Marques, 1984; Manzano, 1986; 
Gámez, 2007). The thickness of this complex attains $60 \mathrm{~m}$ at the center of the delta (Gámez, 2007).

Extensive geological investigations (Figure 5) were performed in the study area. Geological core research ( 3 pairs of piezometers at 15, 20 and $30 \mathrm{~m}$ depth, respectively), 2 borehole logs (natural gamma) and some surface geophysical measurements were performed (for further information see also Bellmunt et al., 2012).

The whole range of facies belts of the Upper Deltaic Complex (subaerial to submarine) were identified in the geological core research (PA1-6; see Figure 5) and described:

- Delta Plain: this facies belt consists of grey and brown clay with intercalations of very fine sand and reaches $2-3$ meters in thickness.

- Delta Front: this is constituted by different lithofacies that grade from silty fine sand to coarser sand with intercalations of gravels in a silty matrix. It ranges from 14 to $15 \mathrm{~m}$ in thickness.

- Prodelta: this is made up of grey clays and silts with intercalations of fine sand and stretches of fine sand with intercalations of silt. It ranges from 20 to $25 \mathrm{~m}$ in thickness. In addition, deeper boreholes near the pilot site (S-1, see Figure 5) and further geophysical measurements were employed to identify deeper geological units. Thus, the bottom of the Prodelta and the top of the Lower Deltaic Complex (predominantly composed of sands and gravels and interpreted as a reworking of alluvial deposits by marine processes in a beach setting and as beach deposits) were established (after Gámez et al., 2009).

\subsection{Hydrogeological settings}


A number of groundwater studies have been conducted in this area in recent decades (e.g., MOP, 1966; Vàzquez-Suné, et al., 2006; Gámez, 2007). From a hydrogeological perspective, the Llobregat Delta consists of different aquifers separated by silt and clay layers of low to medium hydraulic conductivity (Gámez, 2007). Thus, the Prodelta silts of Q4 act as a confining unit separating the upper aquifer (shallow unconfined aquifer) from the main confined aquifer of the Llobregat Delta, which is formed by a very thin and very permeable basin layer of reworked gravels and beach sands and the upper gravels of Q3. The natural gradient of the main aquifer is different from that of the shallow aquifer. The shallow unconfined aquifer is essentially horizontal, with an extension of approximately $100 \mathrm{~km}^{2}$ and a thickness of approximately 15-20 meters.

The geological units at the pilot site were classified in aquifer and aquitard units. Thus, the coarser deposits from the Delta Plain and the sediments from the Delta Front constitute an aquifer unit that corresponds to the shallow aquifer in the delta complex. In addition, the finer deposits of the Prodelta are less permeable and thus act as an aquitard. Finally, the sediments from the reworked channels, beach sands and fluvial channel constitute the main aquifer of the system.

Different piezometers were used in the quantification of the barrier effect. Piezometers were screened at different depths and each piezometer had its equivalent on the other side of the tunnel; a geological section is presented in Figure 5, located on the map in Figure 6d. Thus, PA6 (upgradient) and PA3 (downgradient) were screened above the depth of the tunnel (between depths of 10 and 14 m.b.g.l.) that corresponds to the high hydraulic conductivity Delta Front materials of the shallow aquifer, whereas PA5 (upgradient) and PA4 (downgradient) were screened at the same depth of the tunnel (between 15 and 19 m.b.g.l.) that corresponds to the Delta Front-Prodelta limit (the limit between the shallow aquifer and the aquitard). Finally, PA1 (upgradient) and PA2 (downgradient) were screened below the 
tunnel (between depths of 25 and 29 meters) at a depth that corresponds to the low hydraulic conductivity materials from the Prodelta (aquitard).

The hydrogeological characterization included a slug test campaign to obtain punctual values of parameters of the tested levels. The piezometers were filled with water and the recovery to the initial level was measured manually and with pressure data loggers. The interpretation was completed with the Theis (1935) and Cooper and Jacob (1946) methods, using the MariaJ-EPHEBO code (Carbonell, et al., 1997). The hydraulic conductivity ranged between 0.2 and $4 \mathrm{~m} / \mathrm{d}$ in the upper piezometers (PA3 and PA6), between 0.06 and $0.1 \mathrm{~m} / \mathrm{d}$ in the tunnel layer piezometers (PA4 and PA5) and the lower layer (PA1 and PA2) yielded a lower hydraulic conductivity value of $0.04-0.05 \mathrm{~m} / \mathrm{d}$.

The hydrogeological characterization was completed with the interpretation of two pumping tests performed before the construction of the tunnel. Two fully screened pumping wells 30 m deep were drilled (Figure 6d): pumping Well 1 was located upgradient and pumping Well 2 downgradient. The first test was performed by pumping from Well 1, and when the hydraulic head had almost recovered, pumping started at Well 2. The pumping rates at both wells ranged from $3.5-4.5 \mathrm{l} / \mathrm{s}$. These were measured both manually and automatically using a calibrated barrel and an axial turbine flow meter. Hydraulic head evolution was measured manually (water level dipper) and automatically (pressure data loggers) in all the piezometers and pumping wells for 105 days (this period included the four pumping tests and the pass of the TBM).

The objective of the pumping tests was to estimate the hydraulic parameters of the aquifer (Table 1). In addition, the results obtained allowed for the improvement of the hydrogeological characterization of the area because a recharge boundary or a more transmissive area was identified, which was deduced from the shape of the drawdown evolution. The drawdown slope measured at the shallower piezometers (PA3, PA4, PA5 and 
PA6) decreased with time suggesting their presence. Given that the drawdown slope began to decrease at 0.1 times the characteristic time $\left(t_{C}\right)$ with regards to the length between a piezometer and the image well caused by the presence of a recharge boundary, the position of these boundaries can be approximately determined by using the characteristic time equation $\left(t_{C}=\left(S L^{2}\right) / T\right.$ ), where $S$ is the storage coefficient, $T$ is the transmissivity and $L$ is the distance from the piezometer to the image well caused by the recharge boundary. According to this procedure we determined that the recharge boundary (or a more transmissive area) was located approximately 130-150 m upgradient.

\subsection{Numerical model}

The main geological and hydrogeological aspects explained above were implemented into a numerical model, which allowed the hydraulic parameters of the geological layers to be determined with the data from the two tests performed before tunneling. Subsequently, the different responses of the two post-tunneling pumping tests were simulated using the model.

The numerical model was built using the finite element code TRANSIN-IV (Medina and Carrera, 1996, Medina and Carrera, 2003) with its visual interface VISUAL TRANSIN (GHS-UPC, 2003). The multilayer numerical model has 6 horizontal layers (five hydrogeological layers and an additional layer to correctly locate the tunnel), linked by onedimensional elements. The more transmissive geological layers were implemented as horizontal layers in the numerical model, whereas the materials with low values of hydraulic conductivity (aquitards) were implemented as one-dimensional elements. These elements, whose function is to vertically connect the horizontal layers, do not allow horizontal flow (only vertical). However, this fact is not important because the contribution of the layers, 
which are comprised of low hydraulic conductivity materials (clays or silts), to the effective horizontal transmissivity and, therefore, to the horizontal flow is negligible. The predominant characteristics of the layers of the model are explained below (see also table 1):

- Layer 1 (L1): This layer has a thickness of approximately $1.5 \mathrm{~m}$. It consists of the coarser deposits from the Delta Plain (fine sand with some clay).

- Layer 2 (L2): This layer comprises the shallow aquifer, which is formed primarily by the coarser fraction of the Delta Front (sand and intercalations of gravels). It is approximately $10.5 \mathrm{~m}$ thick. L2b is not a hydrogeological layer located under Layer 2, but corresponds to Layer 2 occupied by the tunnel.

- Layer 3 (L3): This layer is located in the limit between the aforementioned shallow aquifer and the upper part of the Prodelta and consists of sand with intercalations of clay. This layer is $3 \mathrm{~m}$ thick.

- Layer 4 (L4): This layer consists of the coarser part of the Prodelta and its hydraulic conductivity is very low.

- Layer 5 (L5): This layer comprises the main aquifer and has the highest hydraulic conductivity of the model.

- Aquitard1 (1D-D): This aquitard separates layers 3 and 4. It consists of low hydraulic conductivity clay materials from the Prodelta.

- Aquitard 2 (1D-E): This aquitard separates layers 4 and 5 and comprises the lower part of the Prodelta.

Additionally, three one-dimensional elements (1D-A, 1D-B, 1D-C) were included in the model to vertically connect the layers that were not separated by low hydraulic conductivity materials. Thus, the element 1D-A connects layers 1 and 2, the element 1D-B links layers L2 and L2b and element 1D-C connects layers L2b and L3. 
The external boundaries of the model were located $1000 \mathrm{~m}$ from the wells to minimize their influence. The $i_{N}$ in the shallow aquifer at the pilot area was 0.001 . This gradient was achieved by locating a constant rate boundary condition on the northern side to simulate water entering. A prescribed head boundary condition was located on the southern side to simulate water exiting (Figure 7). The vertical hydraulic conductivities of the one-dimensional elements were calibrated to obtain the vertical gradient. The hydraulic heads of the shallow aquifer and main aquifer, which were obtained from a piezometer $60 \mathrm{~m}$ deep located near $(\approx 80 \mathrm{~m})$ the study area (Figure $5 ; \mathrm{S}-1)$, were used in this calibration.

According to the depth of the tunnel, it was implemented in layers $2 b$ and 3 of the model. Four different pumping tests were simulated, from which two were conducted before the construction. Thus, the tunnel was only considered in the model after the TBM passed.

The high hydraulic conductivity area detected previously in the drawdown analysis was regarded as a north-south high transmissivity area in the upper layer. Fully penetrating wells constructed near the study site were also considered in the model. These wells, which hydraulically communicate all the layers (from the shallow to the deep aquifer), reducing the vertical gradient, were implemented in the model as transmissive areas (their dimensions were very small) that connected all the layers.

\section{Results}

\subsection{Barrier effect in natural flow (field measures)}

As discussed above, the permanent effect caused by tunnels implies an increase in hydraulic head upgradient and a decrease downgradient. In the study area, the hydraulic head modification caused by the tunneling was observed at the different pairs of piezometers 
mentioned above. The hydraulic gradient variation between the different pairs of piezometers is shown in Figure 6. The measures taken during the pumping tests are not given because they do not represent the variation at a steady state. After the tunnel's construction, a gradient variation of 5-6 cm was measured in the shallower piezometers (PA6-PA3 and PA5-PA4). Note that the measured hydraulic head variations showed a great deal of noise that was likely a result of natural variations (e.g., recharge by rain) or anthropogenic activities (e.g., pumping or nearby drainage works). Furthermore, when $i_{N}$ is very small, it is difficult to compare the hydraulic head variations measured at different piezometers. The impact in the hydraulic head was not immediate and was observed first in the upper piezometers, then in those screened at the depth of the tunnel. The hydraulic head modification observed at the lower piezometers (PA1 and PA2) was higher than that observed in the others, but the response to the tunneling was inconsistent. Note that the upgradient piezometer (PA1) had a lower initial hydraulic head than the downgradient piezometer (PA2).

\subsection{Barrier effect in natural flow (analytical estimation)}

The barrier effect was calculated by using the equations proposed in Section 2. Because the piezometers were located near the tunnel, only the local barrier effect was computed. Barrier effects between the barrier and the aquifer boundary $\left(s_{B L O}\right)$ and below the barrier $\left(s_{B I}\right)$ were calculated and added. Given that there is a no flow boundary in the half of the tunnel produced by the direction followed by the flow to surround the structure, it is possible to consider only one half of the problem to compute the barrier effect (see Pujades et al., 2012 for details about the symmetry of the barrier effect). Therefore, the layers used to calculate the barrier effect were Layer 1, Layer 2 and Layer 3 (Figure 5), which belongs to the 
shallow aquifer and to the upper part of the aquitard. Thus, the lengths $b, b_{b}$ and $b_{a}$ were 14, 5 and $9 \mathrm{~m}$, respectively (Figure 5). These distances had to be corrected using the anisotropy factor because of the vertical heterogeneity of the aquifer. To obtain the anisotropy factor $\left(\mathrm{a}=\left(\mathrm{k}_{V} / \mathrm{k}_{H}\right)^{0.5}\right)$ the vertical and horizontal hydraulic conductivities $\left(k_{V}\right.$ and $\left.k_{H}\right)$ of the aquifer must be known. $k_{V}$ and $k_{H}$ were calculated using the data from pumping tests as the harmonic and arithmetic averages, respectively, of the hydraulic conductivities of the layers.

$$
k_{V}=b \sum \frac{k_{i}}{b_{i}}=1.75 \frac{\mathrm{m}}{\mathrm{d}} \quad \text { and } \quad K_{H}=\frac{\sum k_{i} b_{i}}{b}=5.16 \frac{\mathrm{m}}{\mathrm{d}}
$$

then,

$$
a=\sqrt{\frac{k_{h}}{k_{v}}}=1.72
$$

Therefore, the corrected lengths $b, b_{b}$ and $b_{a}$ were $24.1,8.6$ and $15.48 \mathrm{~m}$, respectively. Once the vertical distances were corrected, the local barrier effect produced between the boundary of the aquifer and the barrier was computed considering Equation 3 and using $i_{N}=0.001$. Given that $b_{b D}>0.28$,

$$
s_{B L O}=i_{N} b \sqrt{\frac{3}{8}} \ln \left(\frac{2 b_{b D}^{0.29}}{b_{a D}^{2}}\right)=0.019 m
$$

Whereas the barrier effect occurring below the barrier was computed by applying Equation 4,

$$
s_{B I}=i_{N} L_{B}\left(\frac{b}{b_{a}}-1\right)=0.0056 m
$$

The total local barrier effect was obtained by adding both values, 


$$
s_{B L}=s_{B L O}+s_{B I}=0.0246 \mathrm{~m}
$$

This value is lower than that of $s_{B L}$ measured at the piezometers PA4 and PA5 as a result of the tunnel construction (Figure 6). There are two reasons to explain this difference between the computed and the observed $\left.s_{B L}: 1\right)$ the presence of non-identified low hydraulic conductivity layers would increase the anisotropy factor and, therefore, the value of the local effect and 2) the low hydraulic gradient that is perpendicular to the tunnel is used in the analytical solution. Given that $i_{N}$ was small and that it was obtained from field measurements, it could be subjected to errors that are proportionally considerable (inaccuracies in the piezometers references, in the altimetry, in the measurements procedures, as well as caused by those produced by head fluctuations), which would have altered the analytical $s_{B L}$. Note that these errors also can be produced in the field measurements of $s_{B L}$.

Finally, the horizontal effective hydraulic conductivity of the aquifer in the area where the tunnel was constructed was calculated to compare the results of the non-perturbed flow with the results obtained from the pumping tests performed after the tunneling. Given that the $s_{B L}$ calculated is $0.0246 \mathrm{~m}$ and applying Equation 5,

$$
k_{B}=\frac{k}{\left(\frac{s_{B}-i_{N} L_{B}}{i_{N} L_{B}}\right)+1}=2.12 \mathrm{~m} / \mathrm{d}
$$

This value refers to the layers 1 to 3 (shallow aquifer and aquitard).

\subsection{Barrier effect in the pumping tests}

Changes in the local connectivity associated with the construction were studied using pumping tests performed before and after tunneling. These tests allowed for the comparison and quantification of the connectivity reduction caused by the construction of the tunnel. As 
in the synthetic model discussed above, the presence of an "object" that partially obstructs the pathway between a pumping well and a piezometer causes a decrease in the drawdown as a result of pumping. In contrast, if the piezometer is located at the same side as the pumping well (with respect to the tunnel), the drawdown increases because the barrier acts as an impermeable boundary that diminishes the flow to the tested area. Drawdown was analyzed before and after the tunnel excavation to observe the impact of the construction.

Data were pre-processed to compare the different piezometers according to the following steps: 1) The response time related with the distance from the wells to the piezometers was eliminated by dividing the time by the square of the distance (MartínezLanda and Carrera, 2005; Font-Capó, et al., 2011) and 2) The drawdowns were normalized to the flow rate value because it was not constant during the pumping tests.

The drawdown evolution of all piezometers is displayed in Figures $8 \mathrm{a}, 8 \mathrm{~b}$ and $8 \mathrm{c}$. Although each piezometer measured the drawdown during the four tests, only Figure 8 displays the drawdown measured during the tests conducted on the opposite side of the tunnel (i.e., the drawdown shown at the upgradient piezometers was measured during the tests performed pumping from the downgradient side and vice versa). Piezometers PA3 and PA6 (screened at the Delta Front and inside the shallow aquifer) and piezometers PA4 and PA5 (screened at tunnel depth and in the upper part of the Prodelta) behaved similarly (Figures 8a and 8 b). The drawdown response observed in the piezometers (Figure 8) confirmed the theoretical behavior predicted in Section 2 because a delay in the response can be observed. The delay in the response to the pumping was better observed in the deepest piezometers (PA1 and PA2) and in the shallowest (PA3 and PA6). By contrast, a delay in the response to the pumping was not observed at the piezometers PA4 and PA5 because they were screened in the more permeable layers of the aquitard. The different responses to the pumping tests observed before and after the tunneling can be partially attributed to connectivity variations 
between the piezometers and the pumping well. Although PA1 and PA2 were screened in low hydraulic conductivity materials, their response to the pumping was not slow. This suggests that pumping effects, which affect these piezometers, were transmitted quickly through permeable layers located under these piezometers. The results suggest that the connectivity between the deepest piezometers and the pumping well decreased when the permeable layers were obstructed by the tunnel. The reduction of the effective parameters can be obtained by determining $t_{0}$ (Cooper and Jacob method for interpretation of pumping tests) in drawdown evolution during the tests performed before and after the construction and applying

$$
S=\frac{2.25 T t_{0}}{r^{2}}
$$

where $r$ is the distance from the well to the piezometer. Given that the construction could affect the $T$ and $S$, it is possible to assess the impact considering the hydraulic diffusivity ( $\alpha$ ), which is the ratio between $T$ and $S(\alpha=T / S)$. Following this procedure and using the increments of $t_{0}$ observed at PA1 (from 0.0001 to $0.00025 \mathrm{~d}$ ) and PA2 (from 0.00015 to $0.00025 \mathrm{~d}$ ), the value of $\alpha$ is found to decrease between $60 \%$ (considering the data of PA1) and $40 \%$ (considering the data of PA2) from its initial (natural) value. Assuming that the $S$ did not vary a lot, the reduction of $\alpha$ would indicate the same reduction of the $T_{\text {eff }}$ of the aquifer.

\subsection{Numerical results}

The hydraulic conductivity of the modeled layers was obtained by calibrating the numerical model with the data of the two tests performed before the pass of the TBM (pre- 
tunneling tests). Previous values of hydraulic conductivity obtained for different layers from slug tests are consistent with the calibrated ones (Figure 9 and Table 1). Only the hydraulic conductivity calibrated by the model for Layer 3 was greater than those obtained by the slug tests. The difference between both values was probably caused by skin effects or other local effects that occurred during the slug test. Regarding the hydraulic conductivity computed for the different layers of the model, the effective transmissivity of the aquifer before it was crossed by the tunnel was $75 \mathrm{~m}^{2} /$ d. This value refers to Layers 1 to 3 (i.e., the shallow aquifer and top of the aquitard).

The barrier effect was simulated after the calibration of the model. Two scenarios, whose results were compared with the data measured at the field were modeled: 1) simulation of the pot-tunneling tests without implementing the tunnel into the model and 2) simulation of the post-tunneling tests considering the tunnel in the model. The temporal series that included the tunneling process and the repetition of the pumping tests were added to the model in the second scenario.

Heads fitting for scenario 1 in the upper piezometers (PA3 and PA6 in Figure 10) did not show significant differences between the pre- and post-tunneling periods. This fact indicated that the tunnel did not alter much of the behavior of the upper layers. However, piezometers screened at the same depth of the tunnel (PA4 and PA5 in Figure 10) show a bad fit considering scenario 1 . The numerical drawdown computed at the piezometers during the pumping tests performed on the other side of the tunnel (pumping test 3 in PA4 and pumping test 4 in PA5) were lower than the measured one. The numerical and observed hydraulic head agreed at both piezometers when scenario 2 was regarded. Finally, the deepest piezometers showed a puzzling behavior during the tunneling (PA1 and PA2 in Figure 10). The head of the upper and intermediate piezometers increased when the TBM was close to them, whereas 
the head of the lower piezometers underwent a permanent decrease after tunneling, recovering the initial low head that was changed by the pumping tests.

The impact of the construction on the $T_{\text {eff }}$ of the aquifer (in the site where the tunnel was located) was computed comparing the difference in the groundwater gradient through the barrier, which was observed in scenarios 1 and 2 during the post-tunneling tests. The hydraulic gradient between two points is inversely proportional to the transmissivity of the materials located between these two points. The numerical drawdown at PA4 and PA5 during the third and fourth tests was used. Regarding scenario 1, when the pumping was performed for Well 1 (pumping test 3) the drawdown at PA5 (located on the same side of the tunnel as the well) and PA4 (located on the opposite side) reached 2.3 and $1.5 \mathrm{~m}$, respectively, whereas when scenario 2 was considered (during the same pumping test) the drawdowns were 3.4 and $1 \mathrm{~m}$ at PA5 and PA4. The hydraulic gradient through the barrier increased by a factor of 3 , signifying that the $T_{\text {eff }}$ decreased $67 \%$ from its initial (natural) value. The same procedure was followed with the numerical drawdown at the same piezometers during the pumping performed for Well 2 (fourth test). The drawdown at PA4 (located on the same side of the tunnel as the well) and PA5 (located on the opposite side) were 2.4 and $1.6 \mathrm{~m}$, respectively, whereas when scenario 2 was considered (during the same pumping test) the drawdowns were 3.1 and $1.3 \mathrm{~m}$ at PA4 and PA5, respectively. The hydraulic gradient through the barrier increased by a factor of 2.25 , signifying that the $T_{\text {eff }}$ decreased $56 \%$ from its initial (natural) value.

\section{Discussion and Conclusions}


The barrier effect of lined tunnels under natural flow conditions can be forecasted using analytical methods. The hydraulic head impact estimated using the analytical equations of Pujades et al. (2012) in the Sant Cosme site was lower than the measured impact. Differences between the analytical results and the measurements can be attributed to two factors, both of which are associated with the errors caused by the low hydraulic gradient perpendicular to the tunnel $\left(i_{N}=0.001\right)$. Given that the $i_{N}$ was low, the differences in hydraulic heads caused by the barrier effect were also small and therefore, the barrier effect measured in the field could be subject to errors caused by inaccuracies in the piezometer references, in the altimetry, in the measurement procedures, as well as natural or anthropogenic causes produced by head fluctuations. Similarly, the $i_{N}$ measured in the field before the construction, which was necessary to apply the analytical solutions, could also have been subject to inaccuracies. Assuming that the barrier effect was computed analytically (because the measured $i_{N}$ agreed with previous studies performed at the Llobregat Delta River), the reduction in the horizontal effective transmissivity of the aquifer $\left(T_{\text {eff }}\right)$ caused by the construction was determined by analytical methods. The resulting value $\left(29.7 \mathrm{~m}^{2} / \mathrm{d}\right)$ differed from that obtained by the pumping tests performed before the construction of the tunnel, which was $75 \mathrm{~m}^{2} / \mathrm{d}$ (note that both values consider the shallow aquifer and the aquitard; Layers 1 to 3 ). This result implies a large reduction in the transmissivity of the aquifer because the $T_{\text {eff }}$ after the construction was $40 \%$ of the initial transmissivity (a $60 \%$ decrease).

Although analytical methodologies are useful to determine the impact in the hydraulic head caused by the barrier effect and the drop in the connectivity caused by an underground construction, their results may not be acceptable when $i_{N}$ is null or very low (close to 0; as in our case). Furthermore, if $i_{N}$ is null, the impact on the hydraulic heads is non-existent. 
However, the structure affects the aquifer by reducing its connectivity. In these situations, the real impact cannot be assessed by analytical solutions because differences in the hydraulic head are caused by the construction. This fact could cause the impact caused by the construction to be considered as negligible.

Given that the hydraulic gradient perpendicular to the construction in the study site was very low, the barrier effect assessed by the analytical solutions was not completely explanatory because it could be influenced by errors derived from the low hydraulic gradient (as discussed above). Therefore, a procedure based on the pumping tests performed before and after the construction was followed to assess the impact in the aquifer of the construction of the tunnel. The repetition of two pumping tests before and after the tunneling permitted the observation of different responses to the construction. The two theoretical behaviors, an increment of the hydraulic gradient through the barrier and a delay in the response (only at the piezometers located at the opposite side of the tunnel with regards to the position of the well), as described in Section 2, were observed. The increase in the hydraulic gradient through the barrier was better observed in the piezometers screened at the same depth of the tunnel, whereas a delay in the response was difficult to observe in these piezometers because of the elevated hydraulic diffusivity ( $\alpha$ ) of the materials located at this depth (note that $\alpha=T / S$ ). The delay in the response was better observed at the piezometers located under the tunnel. This behavior was likely observed only in these piezometers because they were screened in the materials with the lowest hydraulic conductivity. High transmissivity layers can easily transmit the drawdown, and if they are partially cut, only a very small delay in the posttunneling drawdown is produced, which is difficult to observe. Considering the delay in the response observed in the deepest piezometers (PA1 and PA2) and following a simple procedure, the value of $T_{\text {eff }}$ was calculated to have been reduced by the construction between 40 and $60 \%$ of its initial value. 
Finally, the pumping tests were simulated by a numerical model, where the tunnel was implemented after the two pre-tunneling tests, to determine the groundwater changes caused by the construction. The simulations allowed us to reproduce the permanent tunnel impact caused by the obstruction of the aquifer. Furthermore, given that the model was calibrated with the data from the two pre-tunneling tests, the two post-tunneling tests were simulated considering the tunnel or not. This procedure allowed for the determination of the increment of the hydraulic gradient through the barrier caused by the construction, which was used to compute the reduction caused in the $T_{\text {eff }}$. Regarding the data of the piezometers screened at the depth of the tunnel (PA4 and PA5), the construction was found to have reduced the $T_{\text {eff }}$ of the aquifer between 55 and $67 \%$.

The decrease of the $T_{\text {eff }}$ caused by the construction was computed using three different methods. It was determined that the $T_{\text {eff }}$ of the aquifer was reduced between 40 and $60 \%$, which implies a large impact on the aquifer. Although the three procedures allowed the impact in the transmissivity of the aquifer to be computed, it has to be highlighted that it was possible to apply the analytical procedure because the $i_{N}$ was not null. Furthermore, it was possible to select the best field measured value of $i_{N}$ because of previous projects developed at the Llobregat Delta River, which allowed the site to be characterized conscientiously. At other lesser known sites, analytical predictions may fail as a result of errors associated with field measurements.

The procedure proposed in this paper to assess the barrier effect is useful for predicting the impact of underground impervious constructions at sites where the hydraulic gradient perpendicular to the construction is very low. At these sites, the common errors associated with the field measurements are not negligible with regards to the magnitude of the impact or the magnitude of the hydraulic gradient. Therefore, the analytically computed 
impact is not acceptable because 1) analytical solutions need field measurements $\left(i_{N}\right)$ to be applied and 2) the analytical results also need field measurements to be verified. Furthermore, at sites with a low or null $i_{N}$, the impact on the positions of the hydraulic heads is low, which suggests that the construction would not affect the aquifer. However, the underground structure would have reduced the effective transmissivity and connectivity of the aquifer. These impacts must be considered because they can alter the natural behavior of an aquifer by obstructing the passage of groundwater through the area where the underground structure is located. If the method used in the study site is applied, the impact caused by an underground construction in the connectivity of an aquifer will be better determined. Although this paper is based on the results obtained during the construction of a tunnel by a TBM in a porous aquifer, the procedure would also be applicable for evaluating the barrier effect caused by other underground structures built with other techniques (e.g., cut and cover method) and other types of materials (e.g., rocks). This study also suggests that when an underground construction must be performed, the barrier effect should not only be evaluated analytically. The impact should also be 1) estimated numerically to determine the real impact of the construction in the connectivity of the aquifer and 2) verified by pumping tests before and after the construction. Obviously, a good characterization is necessary because the horizontal and vertical heterogeneity must be introduced correctly. 


\section{Acknowledgements}

The authors would like to acknowledge GISA (Administration) and UTELinia9 (FCC, Ferrovial-Agroman, OHL, COPISA y COPCISA) (Construction company) for their support throughout the hydrogeological monitoring of the civil works. The authors were appointed by GISA as external advisors during the construction of the tunnel. Additional funding was provided by Spanish Ministry of Science and Innovation (MEPONE project: BIA201020244); the Spanish Ministry of Industry (GEO-3D project: PROFIT 2007-2009) and the Generalitat de Catalunya (Grup Consolidat de Recerca: Grup d'Hidrologia Subterrània, 2009SGR-1057). We would like to thank the anonymous reviewers for their comments on the manuscript that have helped improve the revised version of the paper. 


\section{References}

Abarca, E., Vàzquez-Suné, E., Carrera, J., Capino, B., Gámez, D., Batlle, F., 2006. Optimal design of measures to correct seawater intrusion. Water Resources Research 42 (9).

Attanayake, P.M., Waterman, M. K., 2006. Identifying environmental impacts of underground construction Hydrogeology Journal 14 (7), 1160-1170.

Bear, J., Zalavsky, D., Irmay, S., 1968. Hydraulics of wells. Physical principles of water percolation and seepage. Chp. 13, 395-434. UNESCO

Bellmunt, F., Marcuello, A., Ledo, J., Queralt, P.,Falgás, E., Benjumea, B., Velasco, V., Vàzquez-Suné, E., 2012. Time-lapse cross-hole electrical resistivity tomography monitoring effects in an urban Tunnel. Journal of Applied Geophysics 87 (2012) 6070. Doi: 10.1016/j.jappgeo.2012.09.003

Bonomi, T., Bellini, R., 2003. The tunnel impact on the groundwater level in an urban area: a modelling approach to forecast it. Materials and Geoenvironment 50, 45-48.

Butscher, C., Huggenberger, P.., Zechner, E., 2011. Impact of tunnelling on regional groundwater flow and implications for swelling of clay-sulfate rocks. Engineering Geology 117 (3-4), 198-206.

Carrera, J., Vàzquez-Suñé, E., 2009. Sobre la interacción entre acuíferos y aguas subterráneas. In: El agua y las infraestructuras en el medio subterráneo, pp 21-38. AIH-GE and IGME (ed.), Madrid, $470 \mathrm{p}$.

Carbonell, J.A, Pérez-Paricio, A., Carrera, J., 1997. MARIAJ-IV: Programa de calibración automática de ensayos de bombeo. Modelos analíticos y numéricos. ETSECCPB, UPC, Barcelona.

Chae, G.-T., Yun, S.-T., Choi, B.-Y., Yu, S.-Y., Jo, H.-Y., Mayer, B., Kim, Y.-J., Lee, J.-Y., 2008. Hydrochemistry of urban groundwater, Seoul, Korea: The impact of subway tunnels on groundwater quality. Journal of Contaminant Hydrology 101 (1-4), 42-52.

Cooper, H.H. and C.E. Jacob, 1946. A generalized graphical method for evaluating formation constants and summarizing well field history. Am. Geophys. Union Trans., vol. 27, pp. 526-534.

Custodio, E., 1983. Hidráulica de captaciones de agua subterránea. In: Hidrología Subterránea, Vol I, Chap. 9, 614-995. Custodio, E. y Llamas, M.R. (Eds). Editorial Omega, S.A., Barcelona.

Custodio, E., 2010. Coastal aquifers of Europe: an overview. Hydrogeology Journal 18 (1) 269-280. 
Deveughele, M., Zokimila, P., Cojean, R., 2010. Impact of an impervious shallow gallery on groundwater flow. Bulletin of Engineering Geology and the Environment 69 (1), 143 152.

Di Mariano A., Persio, R., Gens, A., Castellanza, R., Arroyo, M., 2009. Influence of some EPB Operation Parameters on Ground Movements. 2nd International conference on computational methods in tunnelling. Ruhr University Bochum 2009, 43-50.

Epting, J., Huggenberger, P., Rauber, M., 2008. Integrated methods and scenario development for urban groundwater management and protection during tunnel road construction: a case study of urban hydrogeology in the city of Basel, Switzerland. Hydrogeology Journal 16 (3), 575-591.

Font-Capó, J., Vàzquez-Suné, E., Carrera, J., Martí, D., Carbonell, R., Pérez-Estaun, A., 2011. Groundwater inflow prediction in urban tunneling with a tunnel boring machine (TBM). Engineering Geology 121, 46-54.

Gámez, D., 2007. Sequence Stratigraphy as a tool forwater resources management in alluvial coastal aquifers: application to the Llobregat delta (Barcelona, Spain). Ph'D Thesis, Technical University of Catalonia, Barcelona, 177. (http://www.tdx.cesca.es/).

Gámez, D., Simó, J.A., Lobo, F.J., Barnolas, A., Carrera, J. Vàzquez-Suné, E., 2009. Onshore-offshore correlation of the Llobregat deltaic system, Spain: Development of deltaic geometries under different relative sea-level and growth fault influences. Sedimentary Geology 217 (1-4), 65-84.

Gargini, A., Vincenzi, V., Piccinini, L., Zuppi, G.M., Canuti, P., 2008. Groundwater flow systems in turbidites of the Northern Apennines (Italy): natural discharge and high speed railway tunnel drainage. Hydrogeology Journal 16 (8), 1577-1599.

GHS-UPC, 2003. Visual Transin Code 1.1 R65. Developed in the Department of Geotechnical Engineering and Geosciences (ETCG), UPC.

Goodman, R.F., Moye, D.G., Van Schaikwyk, A., Javandel, I., 1965. Groundwater inflows during tunnel driving. Bulletin of the Association of Engineering Geologists 2 (1), 3956.

Kvaerner, J., Snilsberg, P., 2008. The Romeriksporten railway tunnel - Drainage effects on peatlands in the lake Northern Puttjern area. Engineering Geology 101 (3-4), 75-88.

López, A., 2009. Estudio analítico del efecto barrera: Definición, tipología, soluciones y aplicación a un caso real. Msc thesis. Universitat Politecnica de Catalunya (UPC). 
Manzano, M., Pelaez, M.D., Serra, J., 1987. Sedimentos prodeltaicos en el Delta emergido del Llobregat. Acta Geologica Hispánica 21-22, 205-211.

Marinos, P., Kavvadas, M., 1997. Rise of the groundwater table when flow is obstructed by shallow tunnels, in: Chilton, J. (Eds.), Groundwater in the urban environment: Problems, processes and management. Rótterdam, Balkema 49-54.

Marques, M.A., 1984. Las formaciones cuaternarias del delta del Llobregat LXXI. Institut d'Estudis Catalans, Barcelona, 1-280.

Martínez-Landa, L., Carrera, J., 2005. An analysis of hydraulic conductivity scale effects in granite (Full-scale Engineered Barrier Experiment (FEBEX), Grimsel, Switzerland). Water Resources Research 41 (3), W03006.

Medina, A., and J. Carrera. 1996. Coupled estimation of flow and solute transport parameters. Water Resources Research 32, no. 10: 3063-3076.

Medina, A., Carrera, J., 2003. Geostatistical inversion of coupled problems: dealing with computational burden and different types of data. J. Hydrol. 281 (4), 251-264. Meier, P.M., Carrera, J., Sánchez-Vila, X., 1998. An evaluation of Jacob's method for the interpretation of pumping tests in heterogeneous formations. Water Resources Research 34 (5), 1011-1025.

Merrick, N., Jewell, M., 2003. Modelling of the groundwater impact of a sunken urban motorway in Sydney, Australia. Materials and Geoenvironment 50, 229-232.

Molinero, J., Samper, J., Juanes, R., 2002. Numerical modeling of the transient hydrological response produced by tunnel construction in fractured bedrocks. Engineering Geology, 64 (4), 364-386.

Mokni, N., Olivella, S., Carrera, J., Otto, B., 2013. Surface movements in a rock massif induced by drainage associated to tunnel excavation. International Journal for Numerical and Analytical Methods in Geomechanics, 37 (9), 1162-1188.

Ministerio de Obras Públicas (MOP), 1966. Estudio de los recursos hidráulicos totales de las cuencas de los ríos Besòs y Llobregat. Barcelona, Comisaría de aguas del Pirineo Oriental y Servicio Geológico de Obras Públicas, 4, 1-50.

Navarro, A., Carrera, J., Sánchez-Vila, X., 1992. Contaminación por lavado piezometrico a partir de vertederos enterrados. Aplicación a un acuifero real. Hidrogeologia y recursos hidraulicos XVI, 371-387.

Pujades, E., López, A., Carrera, J., Vàzquez-Suñé, E., Jurado, A., 2012. Barrier effect of underground structures on aquifers. Engineering Geology 145-146, 41-49. 
Doi:10.1016/j.enggeo.2012.07.004Raposo, R., Molinero, J., Dafonte, J., 2010. Quantitative evaluation of hydrogeological impact produced by tunnel construction using water balance models. Engineering Geology 116 (3-4), 323-332.

Ricci, G., Enrione, R., Eusebio, A., 2007. Numerical modelling of the interference between underground structures and aquifers in urban environment. The Turin subway Line 1, in: Barták, Hrdine, Romancov and Zlámal (Eds.), Underground Space. Taylor and Francis Group, London, pp. 1323-1329.

Sánchez-Vila, X., Meier, P., Carrera, J., 1999. Pumping tests in heterogeneous aquifers: An analytical study of what can be obtained from their interpretation using Jacob's method. Water Resources Research 35 (4), 943-952.

Simó, J.A., Gámez, D., Salvany, J.M., Vàzquez-Suñé, E., Carrera, J., Barnolas, A., Alcalà, F.J., 2005. Arquitectura de facies de los deltas cuaternarios del río Llobregat, Barcelona, España. Geogaceta 38, 171-174.

Theis, C.V., 1935. The relation between the lowering of the piezometric surface and the rate and duration of discharge of a well using groundwater storage. Am. Geophys. Union Trans., vol. 16, pp. 519-524.

Tubau, I., 2004. Estudio Hidrogeológico y propuesta de proceso constructivo para la excavación de un túnel entre pantallas en el delta del Llobregat. Minor thesis. Universitat Politecnica de Catalunya (UPC).

Vàzquez-Suñé, E., Sánchez-Vila, X., Carrera, J., 2005. Introductory review of specific factors influencing urban groundwater, an emerging branch of hydrogeology, with reference to Barcelona, Spain. Hydrogeology Journal. 13, 522-533.

Vàzquez-Suñé, E., Abarca, E., Carrera, J., Capino, B., Gámez, D., Pool, M., Simó, T., Batlle, F., Niñerola, J.M., Ibáñez, X., 2006. Groundwater modelling as a tool for the European Water Framework Directive (WFD) application: The Llobregat case. Physics and Chemistry of the Earth, 31, 1015-1029. Doi: 10.1016/j.pce.2006.07.008

Yang, F.R., Lee, C.H., Kung, W.J., Yeh, H.F., 2009. The impact of tunnelling construction on the hydrogeological environment of "Tseng-Wen Reservoir Transbasin Diversion Project" in Taiwan. Engineering Geology 103 (1-2), 39-58.

Zangerl, C., Eberhardt, E. Loew, S., 2003. Ground settlements above tunnels in fractured crystalline rock: numerical analysis of coupled hydromechanical mechanisms. Hydrogeology Journal 2003, 11 (1), 162-173. 
Zangerl, C., Evans, K.F., Eberhardt, E. Loew, S., 2008a. Consolidation settlements above deep tunnels in fractured crystalline rock: Part 1-Investigations above the Gotthard highway tunnel. International Journal of Rock Mechanics and Mining Sciences 45 (8), 1211-1225.

Zangerl, C., Eberhardt, E., Evans, K.F., Loew, S., 2008b. Consolidation settlements above deep tunnels in fractured crystalline rock: Part 2-Numerical analysis of the Gotthard highway tunnel case study. International Journal of Rock Mechanics and Mining Sciences 45 (8), 1211-1225. 


\section{Figure captions}

Figure 1. Geographical and geological setting of the site area.

Figure 2. a) Synthetic model mesh. b) Tunnel, well and piezometer details. c) Piezometric head around tunnel area $\left(T_{\text {eff }}=0.01\right)$. d) Drawdown around the tunnel $\left(T_{\text {eff }}=\right.$ 0.1). e) Drawdown around the tunnel $\left(T_{\text {eff }}=0.01\right)$.

Figure 3. a) Piezometric head in PZ1 and PZ2 for different $T_{\text {eff }}$ possibilities. b) Drawdown in PZ1 for different $T_{\text {eff }}$ possibilities. c) Drawdown in PZ2 for different $T_{\text {eff }}$ possibilities.

Figure 4. General geological cross section of the Llobregat Delta (original from Simó et al., 2005).

Figure 5. Geological cross section of the site area. Geological description of the exploration boreholes (PA1-6 and S1) and geophysical logs (gamma ray records) are included. Note that the scheme of the model layers are based on the information provided by the borehole PA2.

Figure 6. Barrier effect, piezometric head variation between pairs of piezometers located at the three levels (blue line represents the initial water level and green line the final water level): a) Top piezometers (PZ3, PZ6), b) Bottom piezometers (PZ1, PZ2)), c) Tunnel piezometers (PZ4, PZ5). Note that the plot b) has different scale than plots a) and c). The lower right insets show the piezometers locations around the tunnel and depths (profile). The parameters $b$ (thickness of the aquifers), $b_{a}$ (open fraction of the aquifer) and $b_{b}$ (cut fraction of the aquifer) are also included. 
Figure 7. a) Modeled area with the finite element mesh and boundary conditions. b) Detail of pilot site.

Figure 8. Corrected drawdown $(s / Q)$ versus corrected time $\left(t / r^{2}\right)$ at all the piezometers during the four pumping tests, the two pre-tunneling tests (black points) and the two posttunneling tests (white points). The piezometers compared are screened at the same depth, however one of them is located upgradient and the other downgradient. Upgradient piezometers are on the left, whereas downgradient piezometers are on the right. Figure 8a compares the piezometers screened above the tunnel (PA6 and PA3), Figure 8b compares those screened at the tunnel depth and Figure $8 \mathrm{c}$ those screened below the tunnel. Piezometer screen depths and borehole stratigraphy are in Figure 5 and locations are in Figure 6. Further details in the main text.

Figure 9. Modeled (black continuous line) and measured (dots) piezometric heads during the two pre-tunneling pumping tests used for the hydraulic parameters estimation. Heads are shown for all of the piezometers and wells. The three pairs of piezometers and the pumping wells are compared. Upgradient piezometers and wells are on the left, whereas downgradient piezometers and wells are on the right.

Figure 10. Measured heads (dots) and modeled heads (continuous line grey) with and without the tunnel (continuous line black) versus time of the piezometers and wells from the first pumping test (performed before the pass of the TBM) until the fourth pumping test (performed after the drilling of the tunnel). The three pairs of piezometers and the pumping wells are compared. Upgradient piezometers and wells are on the left, whereas downgradient piezometers and wells are on the right. Two different scenarios are considered and modeled after tunneling, without the tunnel and with the tunnel. 


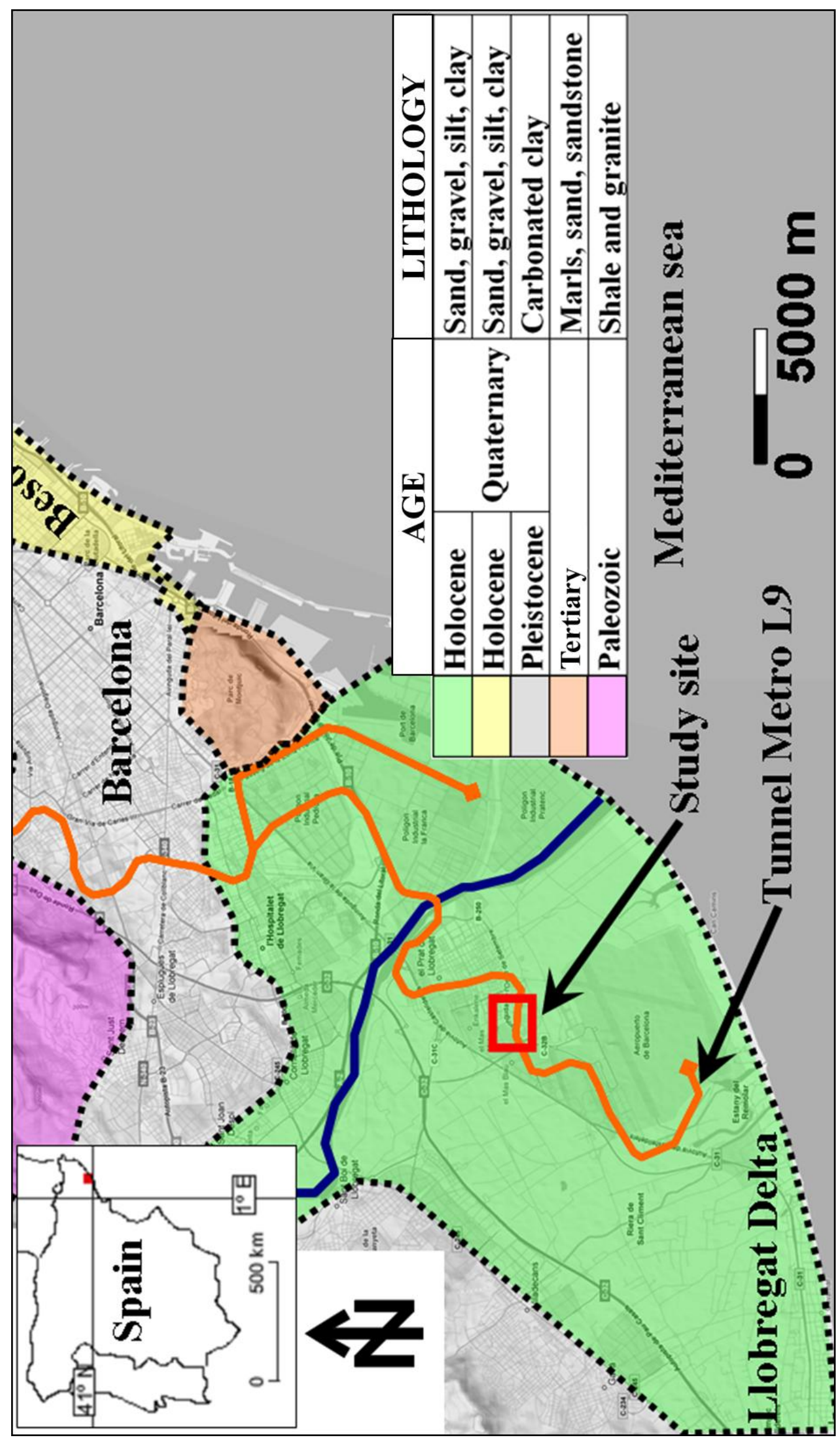

Figure 1 

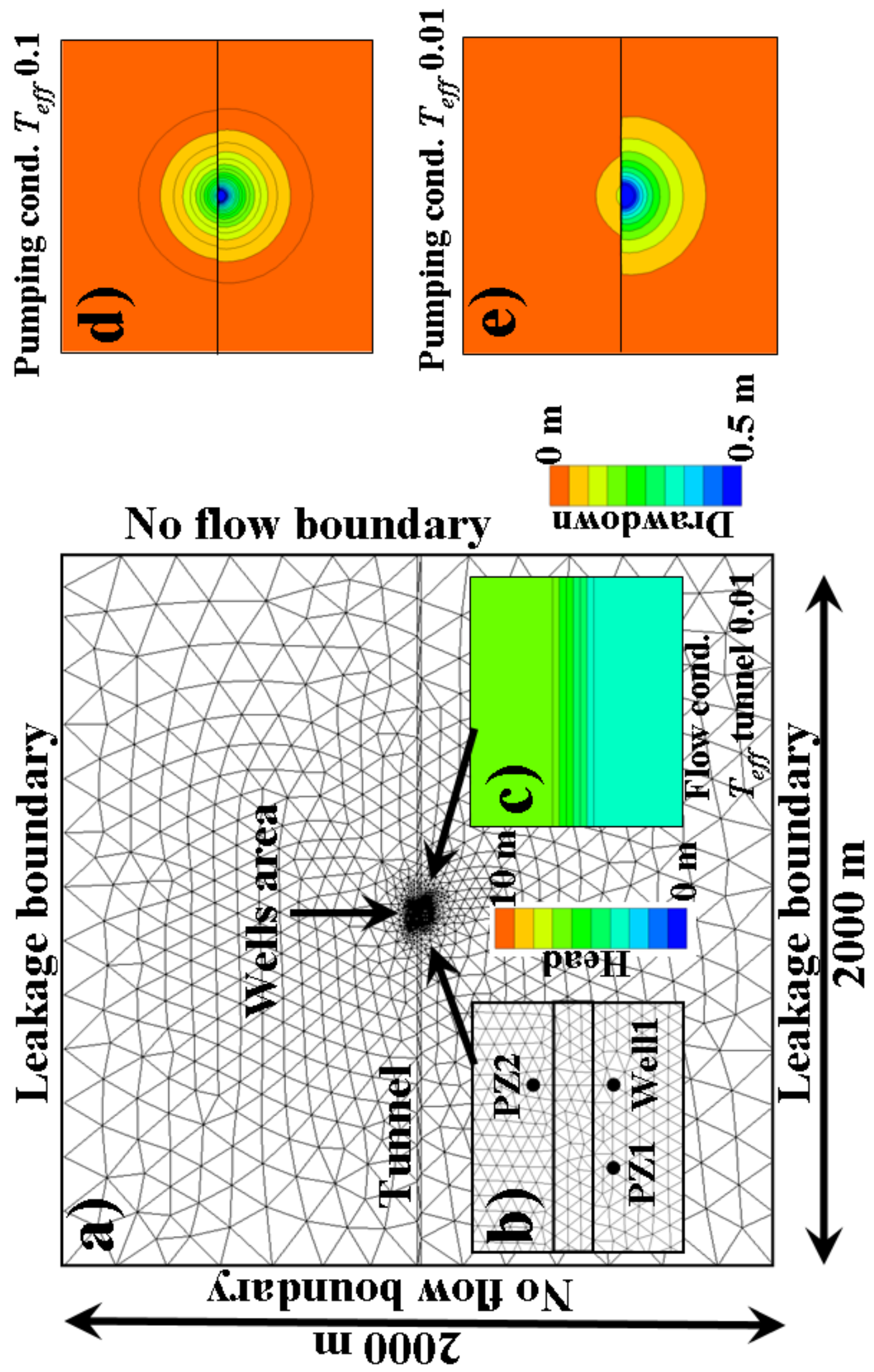

Figure 2 

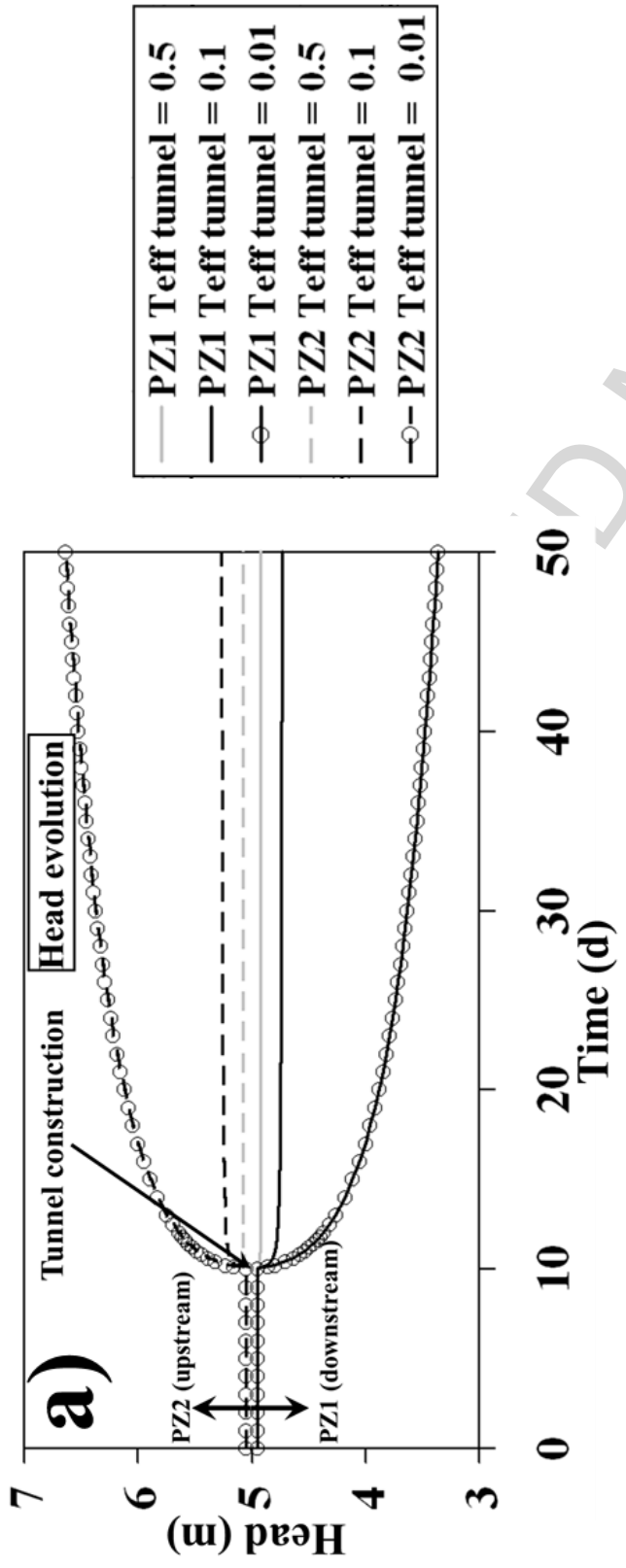
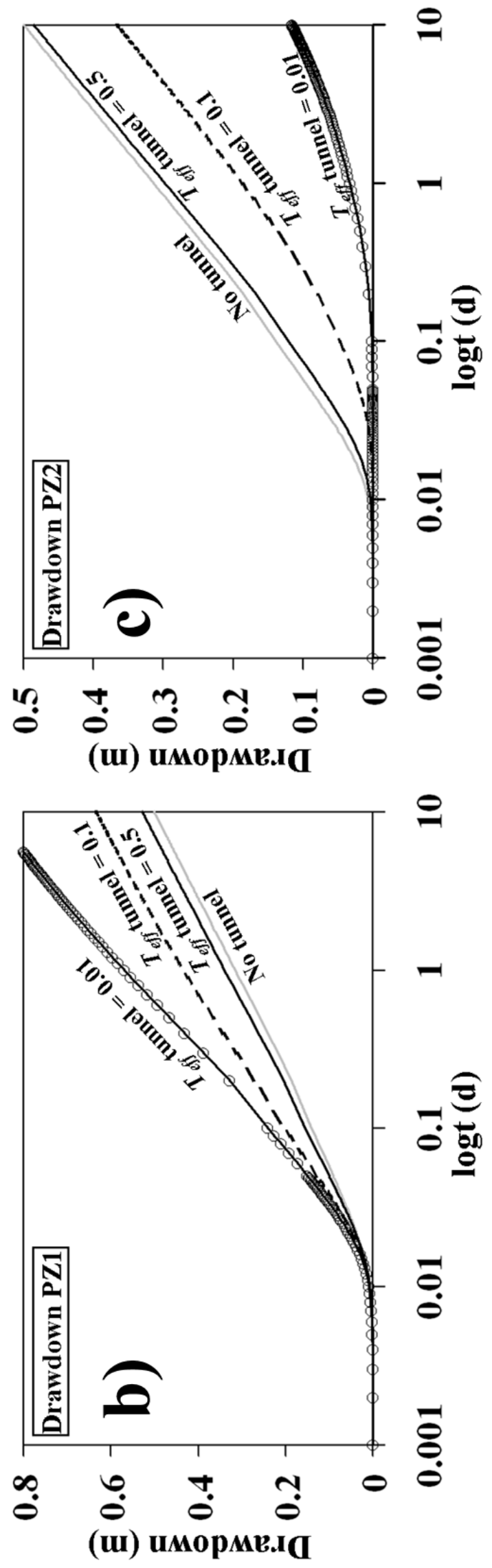

Figure 3 


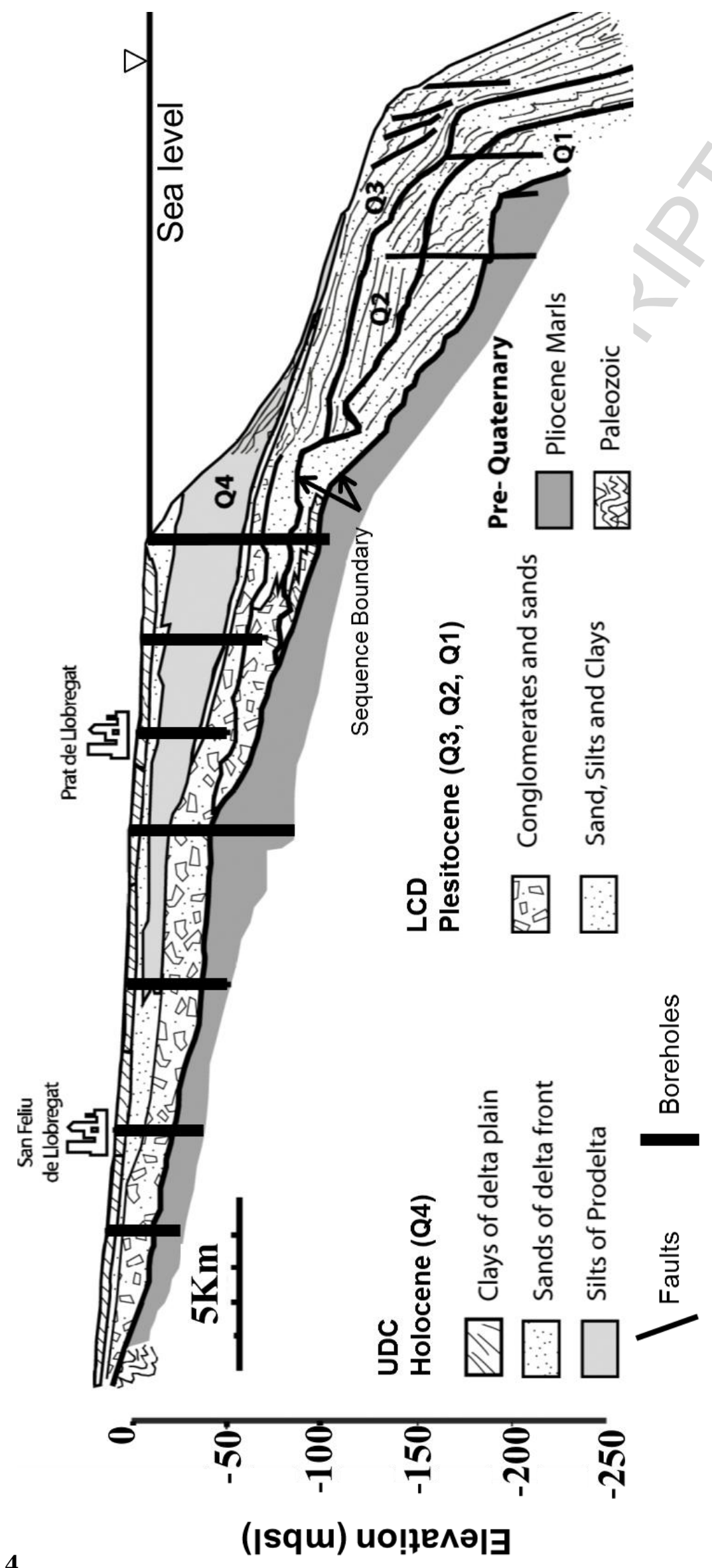

Figure 4 


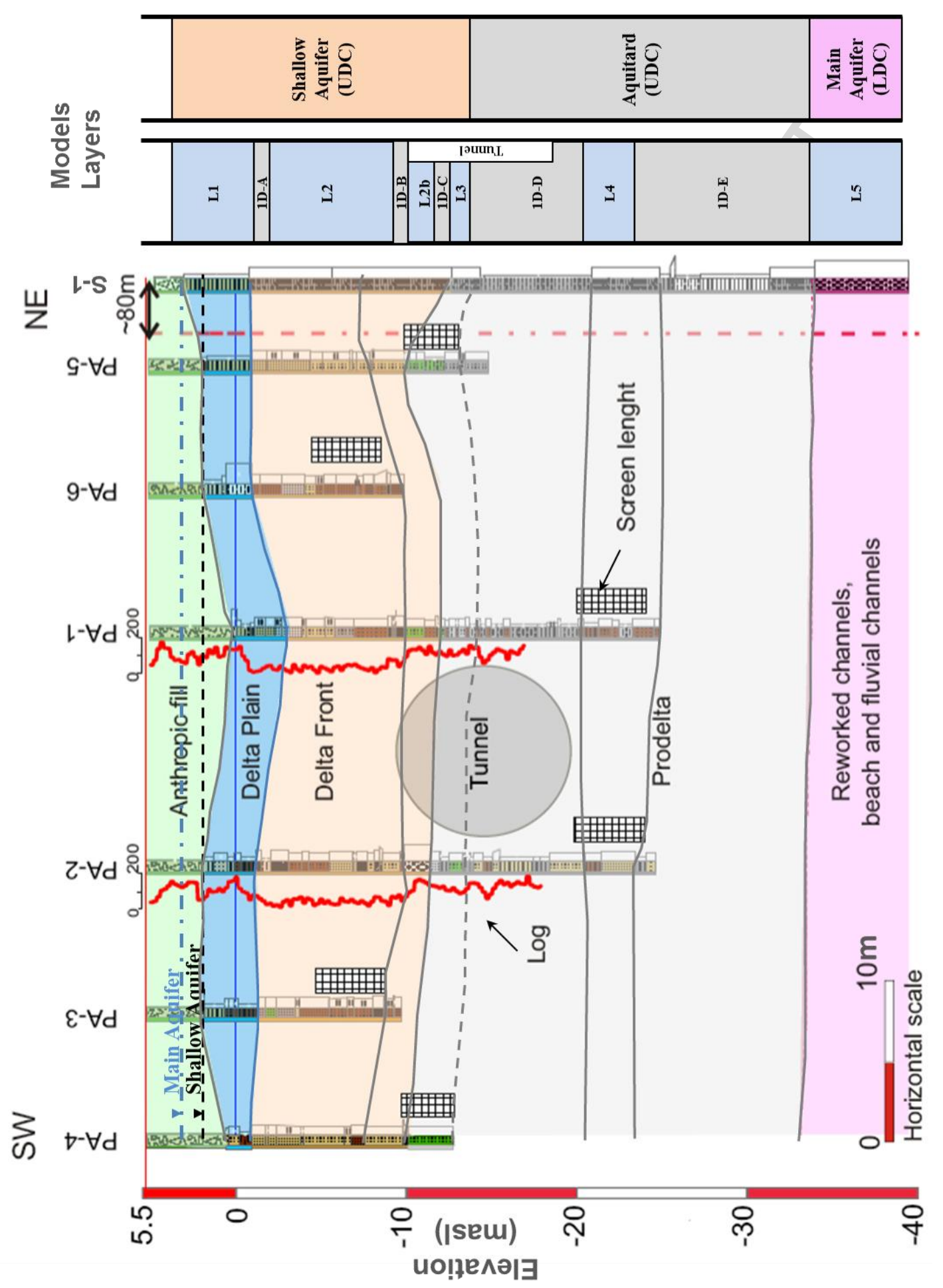

Figure 5 

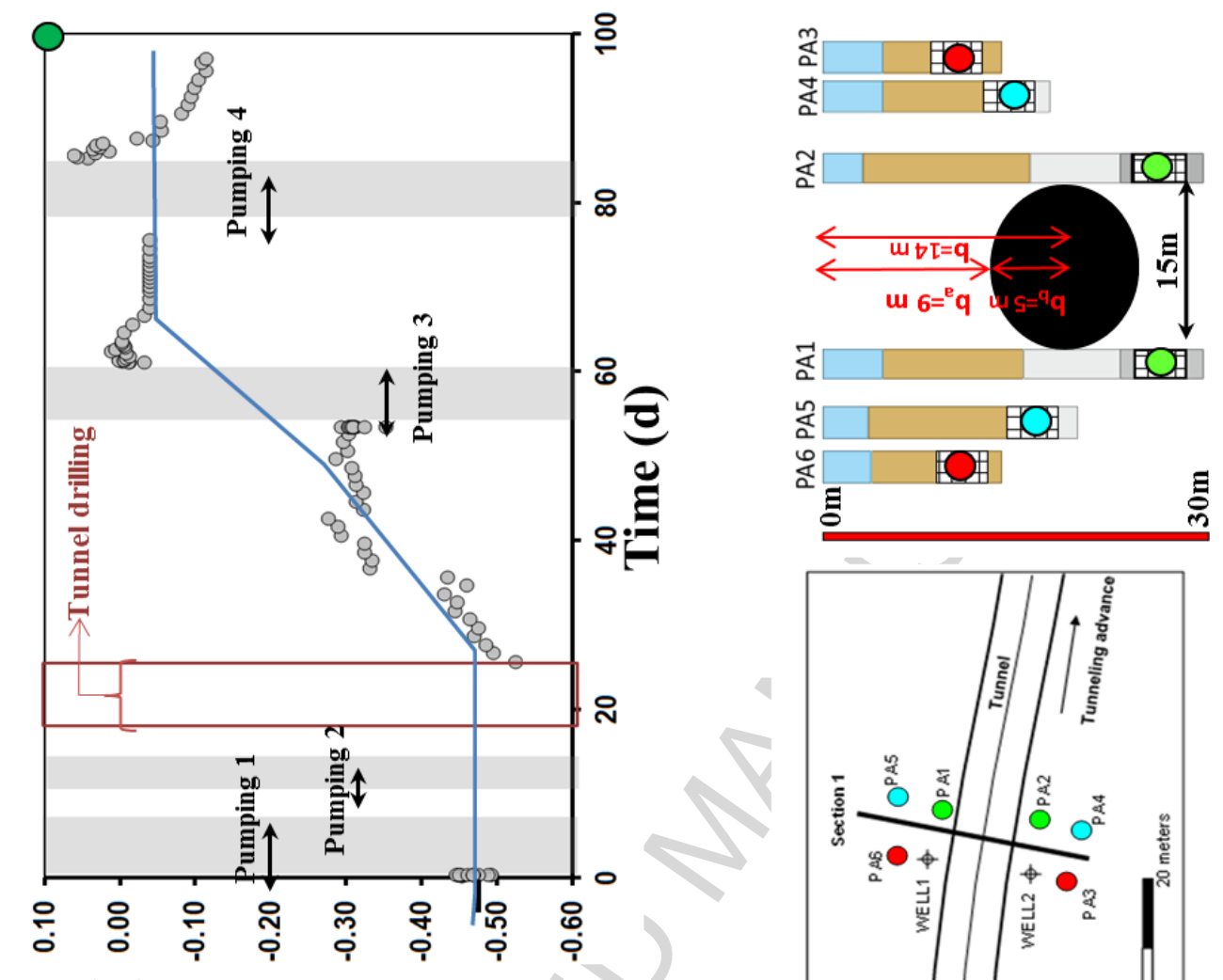

(ui) ZVd-IVdUV

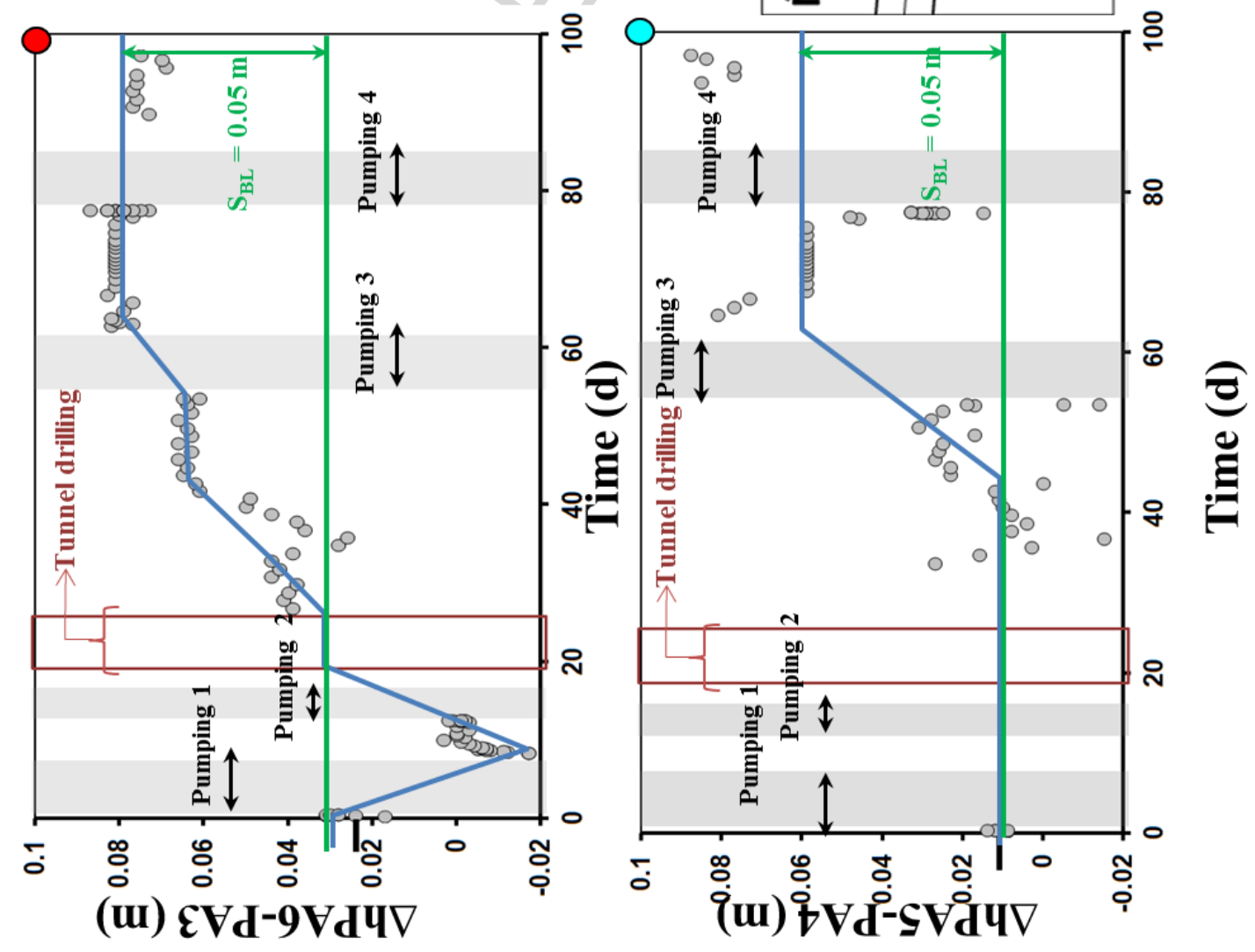

Figure 6 


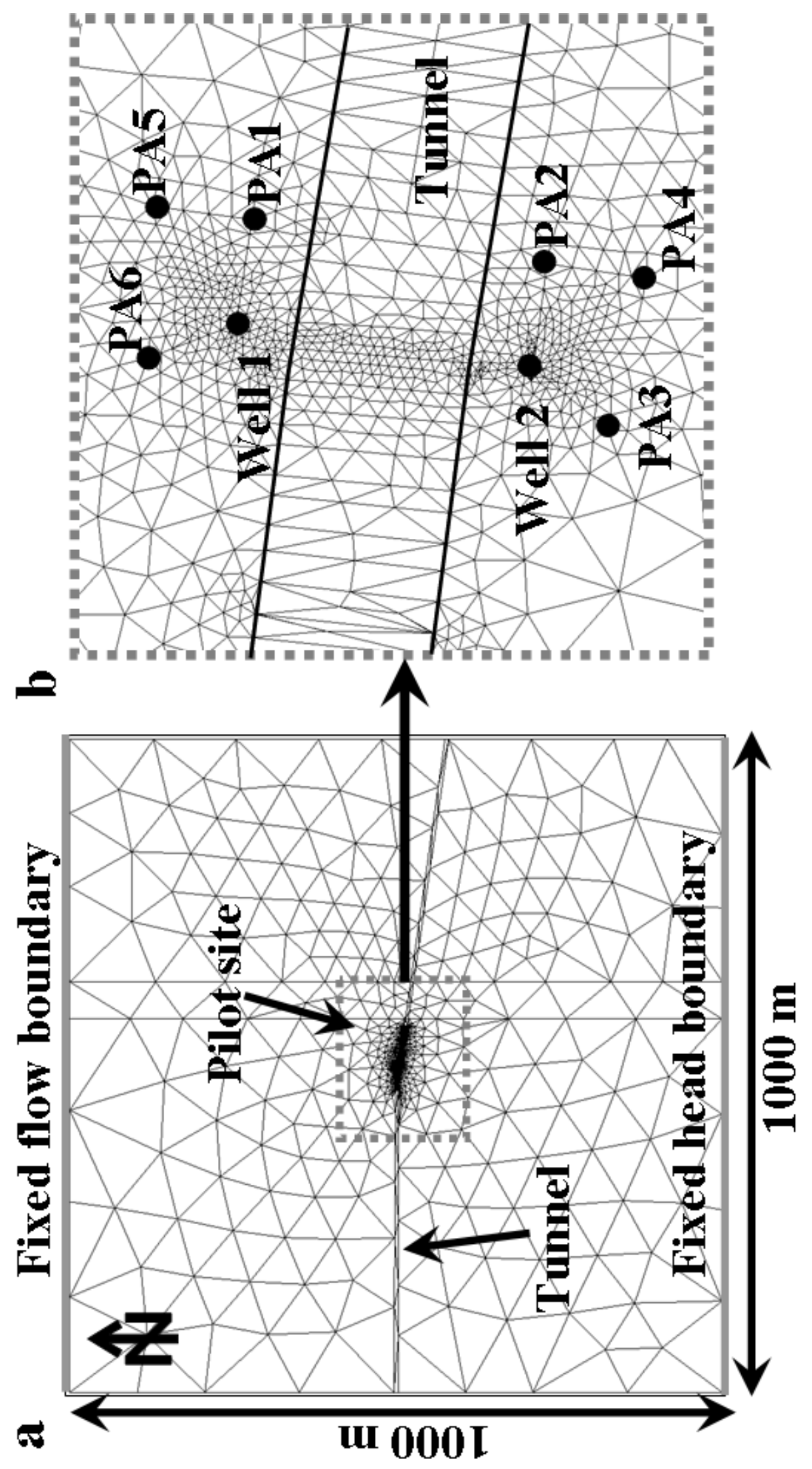

Figure 7 
a)

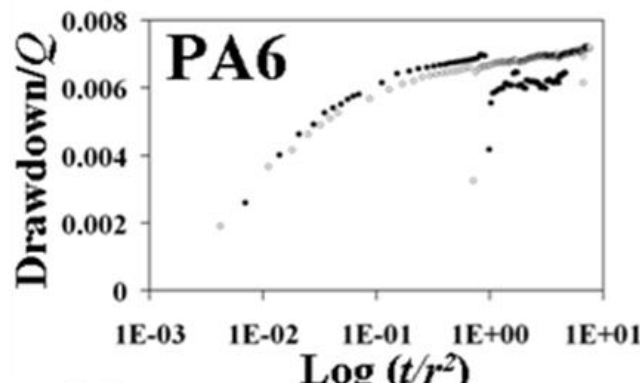

b)

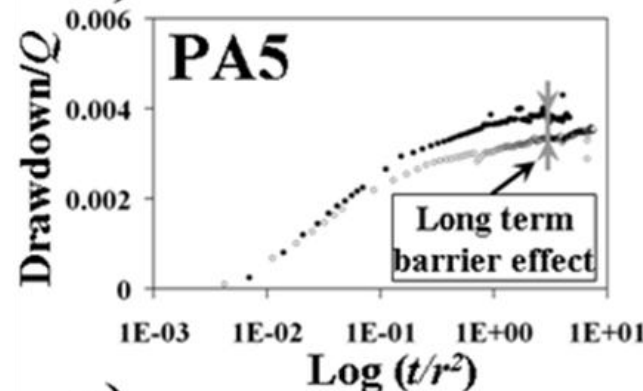

c)

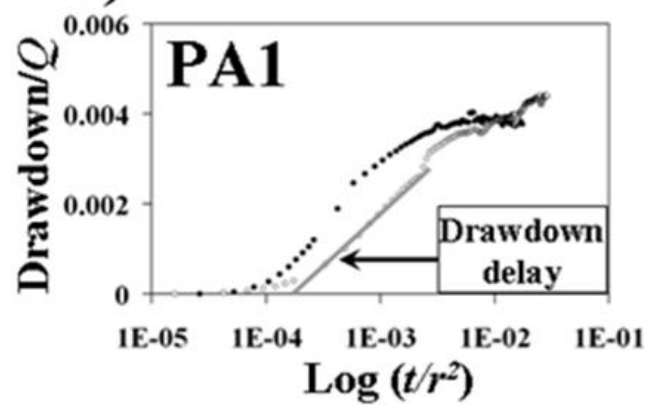

- Pre-tunnelling
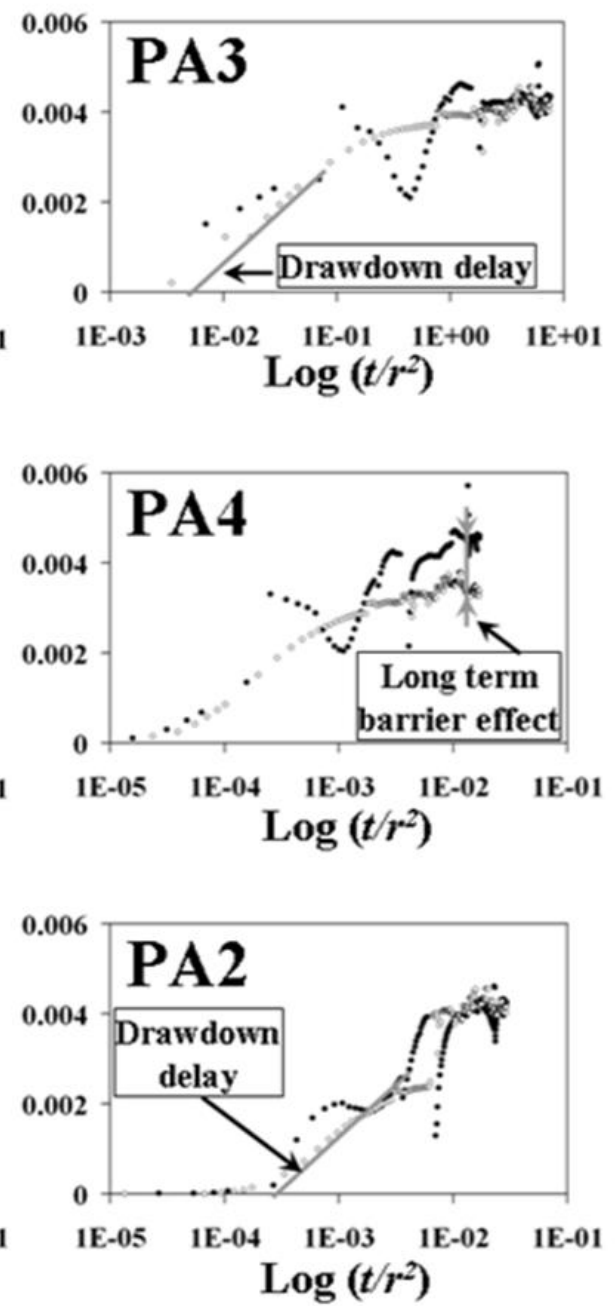

O Post-tunnelling

Figure 8 

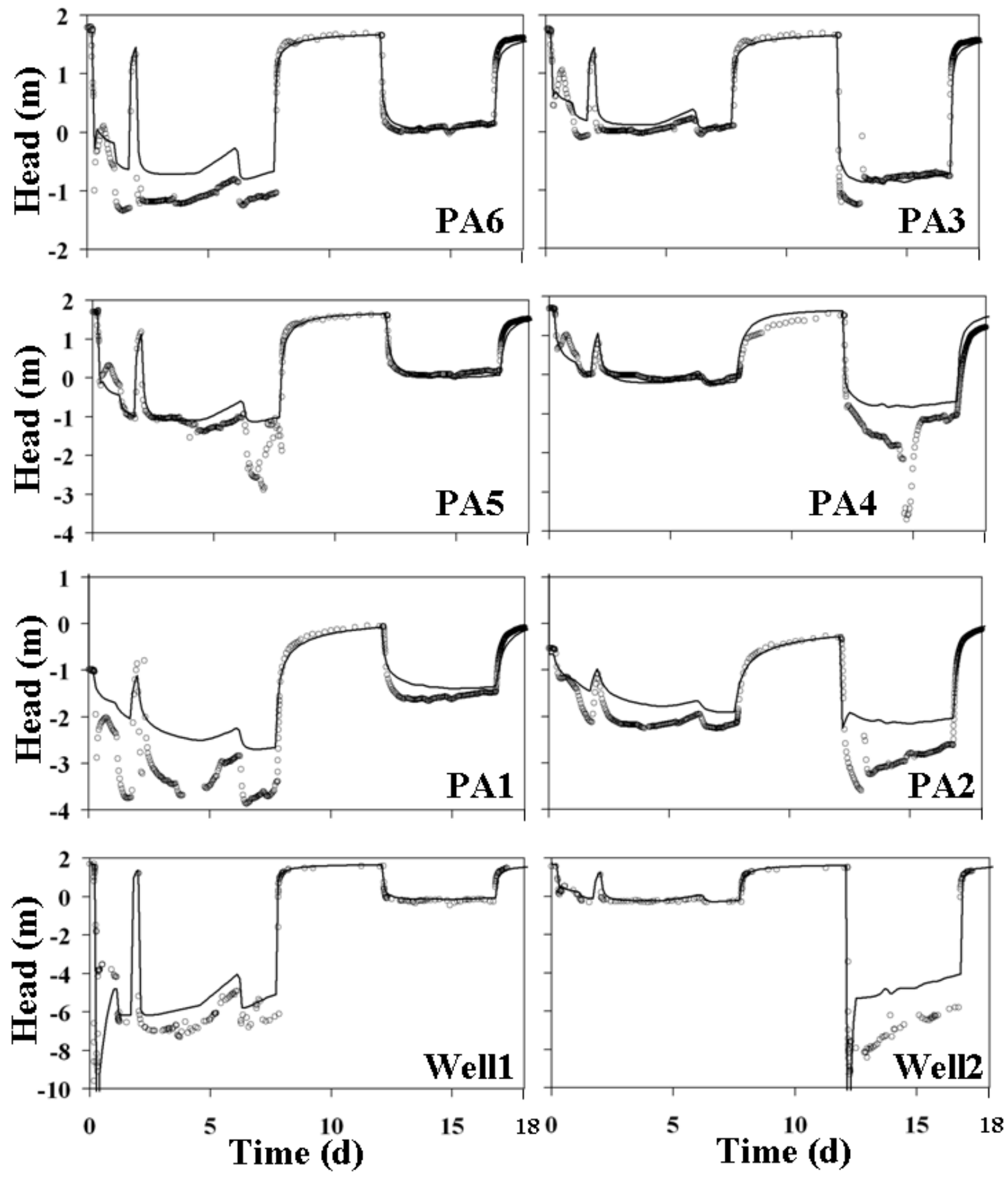

Figure 9 

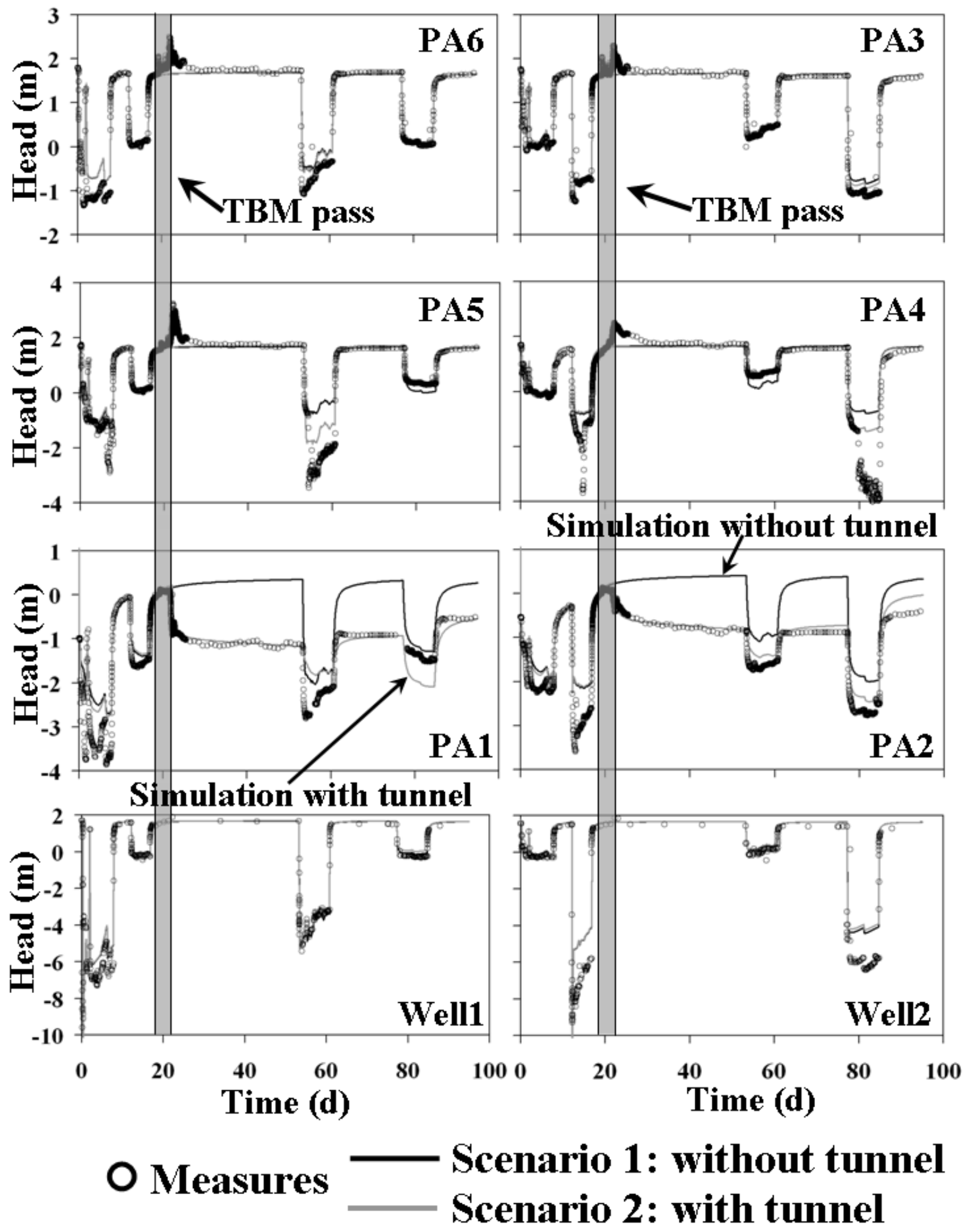

Figure 10 


\section{Table captions}

Table 1. Hydraulic parameters of layers and one-dimensional elements employed in the Model

\begin{tabular}{|c|c|c|c|c|}
\hline & $\begin{array}{c}\text { Hydraulic } \\
\text { Conductivity } \\
\text { Slug Test } \\
\text { (m/d) }\end{array}$ & $\begin{array}{c}\text { Hydraulic } \\
\text { Conductivity } \\
\text { (m/d) }\end{array}$ & $\begin{array}{c}\text { Hydraulic } \\
\text { Conductivity } \\
\text { (m/s) }\end{array}$ & $\begin{array}{c}\text { Storativity } \\
\mathbf{( 1 / m ) ~}\end{array}$ \\
\hline Layer 1 & $0.2-4$ & 0.5 & $5.79 * 10^{-6}$ & 0.01 \\
\hline Layer 2 and 2b & $0.06-0.1$ & 7.5 & $8.68 * 10^{-5}$ & $6 * 10^{-5}$ \\
\hline Layer 3 & $0.04-0.05$ & 1.4 & $1.62 * 10^{-5}$ & $2 * 10^{-4}$ \\
\hline Layer 4 & & 0.02 & $2.31^{*} 10^{-7}$ & $1 * 10^{-6}$ \\
\hline Layer 5 & & 100 & $1.16^{*} 10^{-3}$ & $1 * 10^{-6}$ \\
\hline 1D-A & & 0.0004 & $4.63 * 10^{-9}$ & $1 * 10^{-6}$ \\
\hline 1D-B & & 7.5 & $8.68 * 10^{-5}$ & $1 * 10^{-6}$ \\
\hline 1D-C & & 0.01 & $1.16^{*} 10^{-7}$ & $1 * 10^{-6}$ \\
\hline 1D-D & & $2 * 10^{-7}$ & $2.13^{*} 10^{-12}$ & $1 * 10^{-6}$ \\
\hline 1D-E & & $2 * 10^{-7}$ & $2.13^{-1} 10^{-12}$ & $1 * 10^{-6}$ \\
\hline
\end{tabular}




\section{Highlights}

Impervious tunnels may modify the natural groundwater behaviour.

Impact caused by tunnels may not be perceptible if the groundwater gradient is small

The reduction in aquifer connectivity caused by a tunnel can be assessed by pumping tests

Pumping tests must be performed before and after the construction of the tunnel 